\title{
Cost, Energy and Emissions Assessment of Organic Polymer Light-Emitting Device Architectures
}

Catrice M. Carter, ${ }^{a}$ Justin Cho, ${ }^{a}$ Aaron Glanzer, ${ }^{a}$ Nikola Kamcev, ${ }^{a}$ and Deirdre M. O’Carroll*a,b

${ }^{a}$ Dept. of Materials Science and Engineering, Rutgers University, 607 Taylor Rd., Piscataway, NJ 08854,

USA

${ }^{b}$ Dept. of Chemistry and Chemical Biology, Rutgers University, 610 Taylor Rd., Piscataway, NJ 08854 ,

USA

*Corresponding author. Tel.: +1 848445 1496, E-mail address: ocarroll@,rutgers.edu (D. M. O’Carroll)

\section{Graphical abstract}

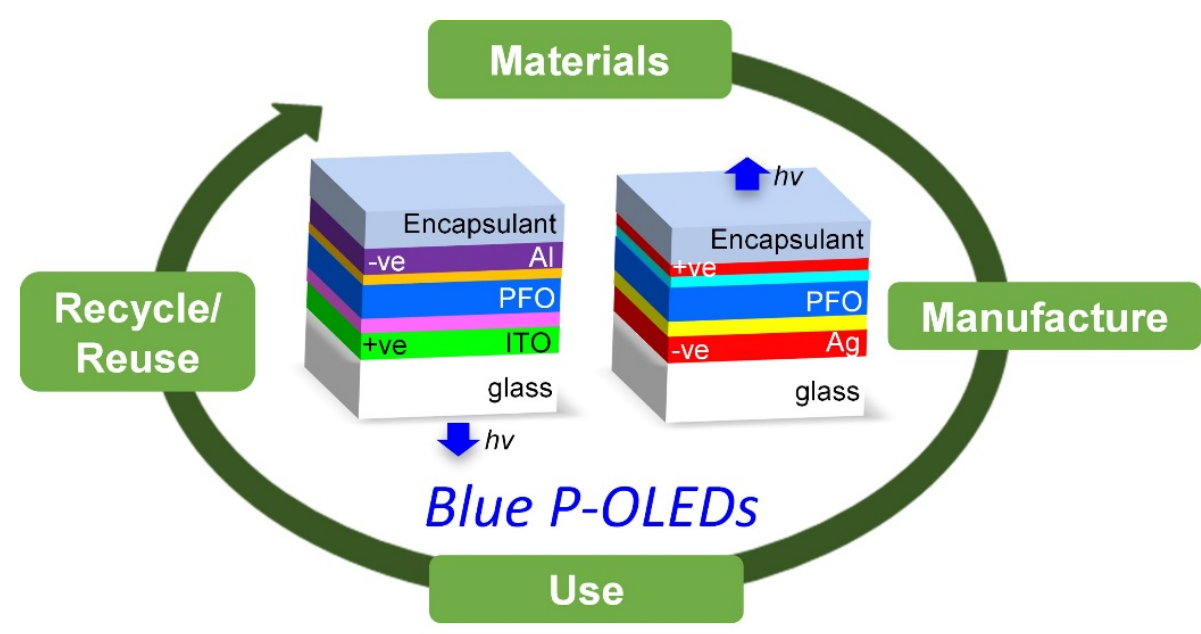

Keywords:polymer OLED; cost; energy; efficiency; life-cycle; greenhouse gas

Total word count: 12153

(C) 2016. This manuscript version is made available under the Elsevier user license http://www.elsevier.com/open-access/userlicense/1.0/ 


\begin{tabular}{|c|c|c|c|}
\hline Abbreviation & Unit & Definition & Description \\
\hline $\operatorname{lm}$ & - & lumen & SI unit of luminous power \\
\hline $\mathrm{cd}$ & - & candela & SI unit of luminous intensity brightness \\
\hline $\mathrm{W}$ & - & watt & SI unit of power \\
\hline $\mathrm{h}$ & - & hour & Unit of time \\
\hline d & - & day & Unit of time \\
\hline $\mathrm{a}$ & - & year & Unit of time \\
\hline $\mathrm{kW} \mathrm{h}$ & - & kilowatt hour & Unit of energy \\
\hline$C_{d e v}$ & $\$ / \mathrm{m}^{2}$ & device costper area & $\begin{array}{l}\text { The total cost of materials and cost to } \\
\text { manufacture a device architecturewith an } \\
\text { area of } 1 \mathrm{~m}^{2}\end{array}$ \\
\hline$C_{o p}$ & $\$ / \mathrm{a}$ & yearly operating cost & $\begin{array}{l}\text { Cost to operate the device for } 8 \mathrm{~h} / \mathrm{d} \text { over a } \\
\text { period of } 1 \mathrm{a}\end{array}$ \\
\hline$C_{l m}$ & $\$ / h$ & optical power cost & $\begin{array}{l}\text { Cost to continuously generate } 1000 \mathrm{~cd} / \mathrm{m}^{2} \\
\text { for } 1 \mathrm{~h}\end{array}$ \\
\hline$G H G-C O_{2, d e v}$ & $\mathrm{~kg}$ & $\begin{array}{l}\text { mass of } \mathrm{CO}_{2} \text { emissionsfrom } \\
\text { device production }\end{array}$ & $\begin{array}{l}\text { Mass of } \mathrm{CO}_{2} \text { greenhouse gas emissions from } \\
\text { raw materials extraction and } \\
\text { manufacturingof a devicewith an area of } 1 \\
\mathrm{~m}^{2}\end{array}$ \\
\hline$E_{\text {mat }}$ & $\mathrm{MJ} / \mathrm{kg}$ & material embodied energy & $\begin{array}{l}\text { Embodied energy of the raw materials in a } \\
\text { device per mass }\end{array}$ \\
\hline$E_{\text {man }}$ & $\mathrm{MJ} / \mathrm{kg}$ & direct process energy & $\begin{array}{l}\text { Energy consumed during device } \\
\text { manufacturingper mass }\end{array}$ \\
\hline$I_{\mathrm{CO} 2}$ & $\mathrm{~kg} / \mathrm{kWh}$ & $\mathrm{CO}_{2}$ emission intensity & Average $\mathrm{CO}_{2}$ emission intensity \\
\hline$G H G-C O_{2, o p}$ & $\mathrm{~kg} / \mathrm{a}$ & $\begin{array}{l}\text { emission mass flow rate for } \\
\mathrm{CO}_{2}\end{array}$ & $\begin{array}{l}\text { Yearly } \mathrm{CO}_{2} \text { emissionsproduced from a } \\
\text { device with an area of } 1 \mathrm{~m}^{2} \text { operating for } 8 \\
\mathrm{~h} / \mathrm{d}\end{array}$ \\
\hline$C_{\text {mat }}$ & $\$$ & $\begin{array}{l}\text { cost of materials in the } \\
\text { device }\end{array}$ & $\begin{array}{l}\text { Cost of raw materials used for adevicewith } \\
\text { an area of } 1 \mathrm{~m}^{2}\end{array}$ \\
\hline$C_{\text {man }}$ & $\$$ & manufacturing cost & $\begin{array}{l}\text { Cost to manufacture a device with an area } \\
\text { of } 1 \mathrm{~m}^{2}\end{array}$ \\
\hline$C_{\text {use }}$ & $\$$ & use phase cost & $\begin{array}{l}\text { The cost to electrically power each device } \\
\text { architecture }\end{array}$ \\
\hline$L$ & $\mathrm{~h}$ & operational lifetime & $\begin{array}{l}\text { The length of time it takes for device } \\
\text { luminous efficacy to degrade by } 50 \%\end{array}$ \\
\hline$C_{\text {elec }}$ & $\$ /(\mathrm{kW} \mathrm{h})$ & $\begin{array}{l}\text { cost of electricity in the } \\
\text { USA }\end{array}$ & $\begin{array}{l}\text { The cost of electricity in the USA per } \\
\text { energy }\end{array}$ \\
\hline$E_{\text {use }}$ & $\mathrm{kW}$ h or GJ & $\begin{array}{l}\text { use-phase energy } \\
\text { consumption }\end{array}$ & $\begin{array}{l}\text { The electrical energy needed to operate a } \\
\text { device over its entire use phase }\end{array}$ \\
\hline$P_{\text {in }}$ & $\mathrm{W}$ & power in & Electrical power applied to the device \\
\hline$M_{v}$ & $1 \mathrm{~m} / \mathrm{m}^{2}$ & luminous exitance & Light output power emitted by a device \\
\hline
\end{tabular}




\begin{tabular}{llll}
\hline$B_{f}$ & $1 \mathrm{~m} / \mathrm{W}$ & luminous efficacy & $\begin{array}{l}\text { Electrical-to-optical power conversion } \\
\text { efficiency }\end{array}$ \\
\hline$k$ & 0.75 & correction factor & $\begin{array}{l}\text { Accounts for device operation at } 75 \% \text { of its } \\
\text { initial luminous efficacy, on average, due to } \\
\text { degradationand efficiency roll-off during its } \\
\text { operational lifetime }\end{array}$ \\
\hline$B$ & $\mathrm{~cd} / \mathrm{m}^{2}$ & luminance & $\begin{array}{l}\text { Used to quantify the brightness of a light- } \\
\text { emitting deviceper area }\end{array}$ \\
\hline
\end{tabular}




\begin{abstract}
Proponents for sustainable alternative lighting and display options advocate for organic lightemitting diodes (OLEDs), particularly polymer-based organic light-emitting diodes (P-OLEDs), because of their potential for low-cost fabrication, more versatile device formatsand lower power consumption compared to traditional options. Here, an economic, energy and $\mathrm{CO}_{2}$ emissionsassessmentis carried out for four different laboratory-scale,blue-emitting P-OLED device architectures: bottom-emitting conventional; bottom-emitting inverted; top-emitting conventional; and top-emitting inverted. Additionally, comparisons with a standard,commercial-scale,blue inorganic light-emitting diode (LED) device architecture are made. The variousP-OLEDdevice architectures are investigated due to their potential to increase operational lifetime (inverted) and light out-coupling efficiency (top-emitting). The following metrics are used in this assessment: device costper area, yearly operating cost, optical power cost, $\mathrm{CO}_{2}$ emissions from device production, and yearly operating $\mathrm{CO}_{2}$ emissions. We show that the topemitting inverted device architecturesignificantly reduces the device costper area, yearly operating cost, optical power costand $\mathrm{CO}_{2}$ emissionsfor the P-OLED devices, due to elimination of indium tin oxide and its comparatively highluminous efficacy and longer lifetime.In addition, the top-emitting inverted POLEDdevice architecture performs competitively at the laboratory scale with commercial-scale inorganic LEDsfor all metrics. However, if top-emitting P-OLEDs are to bemanufactured on a largescale, the luminous efficacy assumed for laboratory-scale devices needs to remain constant throughout developmentto remain competitive.
\end{abstract}




\section{Introduction}

OLEDs are being investigated as sustainable alternative display and lighting options, as opposed to compact fluorescentlamps, incandescentlighting, and LEDs because of their low temperature growth conditions and potential earth-abundant constituent elements (while organic phosphorescent OLEDs usually contain rare-earth elements to harvest triplet excitons, fluorescent OLEDs have active layers thatare primarilycomposed of carbon and hydrogen). However, current small-molecule OLEDs on the market are fabricated under high vacuum using thermal deposition, thus making the fabrication process expensive [1-9]. Therefore, low-cost, large-scale fabrication options are needed to make OLED technologies more marketable.P-OLEDs are an emerging sub-section of OLED technologies that are more amenable to solution-based processing which may enable more straight-forward, vacuum-free fabricationof the devices and, hence, lower cost and lower process energy consumption [2,10-13].

However, the lower efficiency (i.e., luminous efficacy) and the shorter operational lifetime of blue P-OLEDs compared to red and green P-OLEDs, slows the commercialization of a full-color POLED for general lighting and display purposes [2]. The lower efficiency of blue P-OLEDs can be attributed to the difficulty of charge injection into blue-emitting fluorescent polymers which have low highest-occupied molecular orbital (HOMO) energies (ca. $-5.9 \mathrm{eV}$ ) and high lowest-unoccupied molecular orbital (LUMO) energies (ca. $-2.1 \mathrm{eV}$ ) [14]. Common approaches that have been used to remedy these issues are incorporation of a high-work-function hole injection layer, such as poly $(3,4-$ ethylenedioxythiophene):poly(styrenesulfonate) (PEDOT:PSS), and a low-work-function electron transport layer, such as calcium $(\mathrm{Ca})$ or lithium fluoride $(\mathrm{LiF})$ into the device structure [15-17]. Additionally, while internal quantum efficiency can be optimal ( $100 \%$ for phosphorescent OLEDs and phosphorescent P-OLEDs) [18], light-extraction efficiency is quite low ( 20\% to 31\%) [18-20], especially for blue-emitting devices and is a significant barrier to high-efficiency P-OLEDs. The shorter operational lifetime ofconventional blue, fluorescentP-OLEDs is due to a combination of: (1) higher drive voltages due to the low light extraction efficiency; (2)corrosion of indium tin oxide (ITO) due to the 
acidity of the PEDOT:PSS layer [3,21] and (3) degradation of PEDOT:PSS and Ca carrier injection properties due to exposure to water vapour and oxygen during device fabrication or operation [3].

Proposed approaches to tackling efficiency and operational lifetime issues are: (1) light management approaches, such as use of top-emitting device architectures, and addition of metallic or dielectric nanostructures to promote more efficient light extraction [22]; (2)inverted device architectures [23]; (3) improved encapsulation methods [24]. While these approaches have been shown to have the potential to increase device efficiency and operational lifetime [22-24], they may in turn affect the overall cost and environmental impact. Thus, further assessment of these approaches must be completed before any definitive conclusions can be drawn as to their usefulness. The goalof this study is to carry out an cost, energy and $\mathrm{CO}_{2}$ emissions assessment, based on life-cycle assessment (LCA) methodologies, for four laboratory-scale, prototypical, fluorescent, blue-emitting P-OLED device architectures (conventional bottom-emitting, inverted bottom-emitting, conventional top-emitting and inverted top-emitting architectures) to determine which architecture is more effective in terms of device cost per area, yearly operating cost, optical power cost, energy consumption, and $\mathrm{CO}_{2}$ emissions. Additionally, comparisons are made with the more ubiquitous, commercial-scale, blue inorganic LED device. As discussed earlier, the inverted P-OLED architectures increase the operational lifetime and the top-emitting P-OLED architectures increase the electrical-to-optical power conversion efficiency (i.e., luminous efficacy) $[3,8,23]$.

Several economic and LCA studies have been conducted for LEDs and organic photovoltaic (OPV) devices which form the basis of our study for P-OLEDs [4-7,25-39]. Acase study for the LCA of LED downlight luminaires concluded that the environmental impact of LEDs is dominated by the usestage energy consumption and data gaps exist in LED product manufacturing and its environmental impacts; thus, resulting in a need for further research and assessments in order to compare LED-based luminaires with existing lighting technologies [28]. The U. S. Department of Energy has carried out detailed LCAs of energy and environmental impacts of LED lighting products, which show that the average life-cycle energy consumption is similar for both compact fluorescent lamps and LEDs, with it 
being greater for incandescent lamps [7]. While economic, energy and environmental assessmentshave been completed for inorganic LEDs not much emphasis has been placed on the organic counterpart, which motivates this study. We draw comparisons with polymer-based OPV device economic and LCA studies, where applicable, since there have been a significant number of such studies [4-6,22,27-39] and, while OLEDs and OPV devices are operationally different, their device compositions and architectures are similar.As a result, one can study prior work on OPVs in order to draw inspiration to base future organic polymer-based cost and LCA studies due to the similarities in device structure and material type with the main difference being that polymer-based OPVdevices produce electrical energy from sunlight whileP-OLEDs consume electrical energy to produce light.

Furthermore, numerous OPV studies have focused on identifying approaches to lower device cost and the effects of increasing the efficiency and operational lifetime on energy and greenhouse gas (GHG) emission metrics that are also pertinent to P-OLEDs. For example, alife-cycle and cost assessment of OPV devices by Emmott et al. explored various transparent conductor alternatives to ITO in which they found that material alternatives, such as silver nanowires and high-conductivity PEDOT:PSS, have the potential to reduce the energy-payback time (EPBT) and financial cost of organic photovoltaic devices [4]. Espinosa et al. conducted a LCA of organic tandem solar cells where they investigated the economic and environmental feasibility of manufacturing a tandem solar cell versus a single junction solar cell. They found that the tandem solar cell has to be $20 \%$ better performing than a single-junction device in order to improve cost and sustainability metrics [27]. A review paper by Lizin et al. of LCA studies of OPVs focused on environmental aspects such as cumulative energy demand (CED), EPBT, and the GHG emission factor of single-junction,organic,bulk-heterojunction $\mathrm{P} 3 \mathrm{HT}: \mathrm{PC}_{60} \mathrm{BM}$ polymer-based solar cells [5]. The top environmentally performing solar cell had a CED of $37.58 \mathrm{MJ} / \mathrm{m}^{2}$, EPBT from 3.54 months to 6.24 months, and cell efficiency of $2 \%$ with lower GHG emission factors than current power plants. They concluded that the often-used linear relationship between increasing operational lifetime or efficiency and improved sustainability, CED and EPBT, is not a sufficient model because improvements in these areas are heavily dependent on the device materials and architectures [5]. Darling et al. conducted 
a LCA to estimate the $\mathrm{CO}_{2}$ emission factor for a OPV device with an area of $1 \mathrm{~m}^{2}$, with $1 \%$ solar power conversion efficiency (PCE) and one year operational lifetime (which are achievable today), and a hypothetical future OPV device with 15\% PCE and a 20 year operational lifetime [6]. They estimated a $\sim 10 \%$ decrease in $\mathrm{CO}_{2}$ emissions due to the increase in PCE and the longer operational lifetime. Furthermore, they suggest that improvements can be made to operational lifetime through encapsulation with materials with low water and oxygen transport rates and use of air-stable alternative materials. Additionally, in order to transfer OPV technology from laboratory-scale to larger scales for commercialization, efficiency, scalability of manufacturing processes, and knowledge of degradation mechanisms and their impacts on operational lifetime are critical factors that have been identified through economic and LCA studies [5,6,29-39].

The aforementioned OPV studies allow us to draw some conclusions that are applicable to POLED devices, such as: eliminating ITO from the device architectures, increasing multilayer device performance, and use of stable device materials and encapsulants should assist in making P-OLED performance more comparable with the performance of current LEDs on the market. However, comparisons between certain aspects such as life-cycle $\mathrm{CO}_{2}$ emissions and cost assessments of photovoltaic devices and light-emitting devices are not appropriate or straight forward. For example, once a photovoltaic system is installed, the main yearly cost is associated with system maintenance, while, for a lighting system there are significant additional costs because it consumes electricity during operation (as opposed to generating electricity from a free natural resource, i.e. the sun, as in the case of a photovoltaic system). Therefore, in our study we develop some alternative assessment methodologies and metrics that are relevant to P-OLED devices but not to OPV devices.

\section{Methodology}

\subsection{Goal and Scope}


As mentioned in Section 1, the goal of this study is to carry out acost, energy and $\mathrm{CO}_{2}$ greenhouse gas $\left(\mathrm{GHG}-\mathrm{CO}_{2}\right)$ emissions assessment, based on LCA methodologies, for four laboratory-scale, prototypical, fluorescent, blue-emitting P-OLED device architectures to determine which architecture is more effective in terms of device cost per area, yearly operating cost, optical power cost, energy consumption, and $\mathrm{CO}_{2}$ emissions. LCA is used as a tool to assess the energy and environmental impacts of a product, process or activity throughout its life cycle; from the extraction of raw materials through to processing, transport, use and disposal [4,5,7,25-42]. LCA is a standard international ISO 14040 series method that consists of four distinct components: (1) goal and scope, (2) inventory analysis, (3) impact assessment, and (4) interpretation. First, the aim of the study, central assumptions, and system boundaries are chosen. Next, during the life-cycle inventory analysis (LCI) phase, the inputs and outputs for the emissions and resources are quantified. Then a life cycle impact assessment (LCIA) is conducted to evaluate the potential environmental impact of the previous quantified values. Finally, an interpretation of results are presented in a clear concise manner[27,41,42].

We complete cradle-to-grave assessment, i.e.,from the inception of raw materials to the end of use, of afluorescent, blue-emittingP-OLED device (i.e., one that uses, for example, a polyfluorene-based light-emitting active layer) as there are numerous results reported in the literature for such devices $[1,3,8$ 14]. As discussed in Section 1, while photovoltaic studies can be used as a guide to base LCA studiesof light-emitting deviceson,they differ in terms of their operation. Unlike OPVs, P-OLEDs consume electrical power for operation and produce optical power (i.e., light). As a result, the functional unit should be determined by the basis of the optical power produced, which in our case we are assuming to be thebrightness per area or luminance. Therefore, here, we employ a luminance of $1000 \mathrm{~cd} / \mathrm{m}^{2}$ as our functional unitwhich is a commonly reported luminance for OLEDs[2,24,43-50]. Each device architecture is assumed to produce this constant brightness, and in order for this to be achieved either the electrical input power or the power efficiency (i.e., luminous efficacy) of the device can be varied. Note that in contrast, for OPV devices a constant optical input power (or irradiance) is applied during performance testing (i.e., $100 \mathrm{~mW} / \mathrm{cm}^{2}$ (1 sun)); therefore, to generate a particular target electrical power quantity, 
device area or efficiency is varied. We determine the following metrics: the device costper area, including materials and manufacturing costs;yearlyoperational cost; cost to continuously generate 1000 $\mathrm{cd} / \mathrm{m}^{2}$ for one hour; and the GHG- $\mathrm{CO}_{2}$ emissions, for both device production and yearly operation, from the point of view of the user. The assessment carried out here is meant toprovide perspective on the cost, energy and emissionsimpact of blue-emitting P-OLEDs relative to the more mature inorganic semiconductor LED technologies. Additionally, the P-OLED life-cycle stages and materials which are expected to have the greatest costand emissionsimpacts are identified.

\subsection{Central Assumptions}

In this study, we completed a cradle-to-graveassessmentincluding the following stages (Fig. 1): (1) raw materials extraction and production; (2) PLED device fabrication and (3) PLED device use.The following inputs and outputs are considered for each stage where relevant: material inputs; electrical energy inputs; GHG- $\mathrm{CO}_{2}$ emissions outputs and optical energyoutput, and P-OLEDdevice use stages.A life-cycle inventory is compiled and analyzedfor the materials, production and fabrication, and use-phase operating cost of the PLEDs in order to carry out the assessment.In our assessment, we ignore all transport, installation, and disposal phase costs associated with the life-cycle of the P-OLED because these costs are assumed to be small compared to device and use-phase costs $[4,31,40]$. Furthermore, we have not included in the assessment the housing, electrical connections, heat sinks, or others items involved in the mounting of the P-OLED as it is assumed to be similar amongst the different P-OLED architectures regardless of the final product (e.g., lighting, display) because they are all planar, thin-film surface-emitting optoelectronic devices and our functional unit (i.e., $1000 \mathrm{~cd} / \mathrm{m}^{2}$ ) is the same for each architecture. Conversely, for the inorganic LED different housing, mounting and peripheral components (e.g., electrical connections, heat sinks) could certainly be employed. However, given that the blue inorganic LED is the most ubiquitous blue light-emitting device, it is useful as a standard against which blue OLEDs can be compared (similar to how a silicon solar cell is the standard against which all newer solar cell technologies are compared regardless of eventual differences in mounting, housing, etc. [6]). 


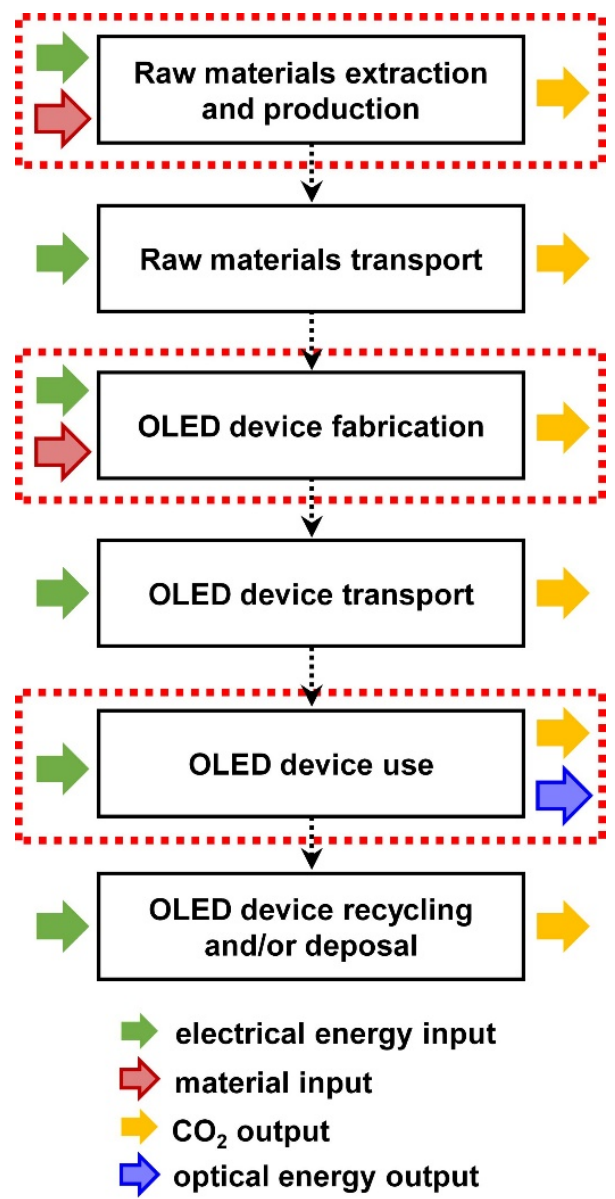

Fig. 1.System boundary diagram for a LCAofOLEDs. In this study, our assessment considersonly the stages of the life cycle highlighted in by the dashed red boxes: raw materials extraction and production, OLED device fabrication, and OLED device use.

Our background system (i.e., the information needed to carry out this study) is defined through extensive reviews of published literature and supplier catalogues. Embodied energy and direct process energy values were obtained from published literature that included relevant embodied energy data from LCA databases such as Ecoinvent and Gabi for the more common materials (e.g., glass, silver).However, in some cases, material embodied energy values were assumed values based on more commonly-available materials within the same material class. For example, material embodied energies for poly(3hexylhiophene) were used instead of those for poly(9,9-dioctylfluorene)), PFO, for the organic conjugated polymer active layer due to lack of available embodied energy data for PFO. This is a reasonable approach because both $\mathrm{P} 3 \mathrm{HT}$ and $\mathrm{PFO}$ are conjugated (i.e., semiconducting) polymers that have rigid 
molecular backbones that consist of molecular monomers or long chains of carbon-based repeat units connected by covalent bonds. In addition, both polymers are synthesized from a solution in a similar catalytic fashion [51,52]. The cost per massdata for materials were obtained from supplier online catalogues and from published literature. References to the source websites (including date accessed) and the relevant papers are included at the appropriate location for each cost per massvalue. For the thickness of layers in the different P-OLED devices (Tables 1 and 2), information was obtained from published literature in which device prototypes were fabricated and tested, as well as Department of Energy solidstate lighting technical reports (referenced below).

The performance parameters (Table 3) are essential to calculating the metrics defined in Section 2.3 used for the assessment of the different device architectures, which comprise our foreground system. Note that only lab-scale and pilot-scale fluorescent blue polymer OLED devices have been reported to date. Therefore, all of our metrics for the OLED devices are for lab/pilot-scale devices. First, the average operational lifetimes of conventional blue fluorescent OLEDs were determined from references [2,43,44]. Then, based on publications in which direct comparisons between the lifetime of a conventional and inverted OLED were made [45,46], a scaling factor was determined. From this assessment we found that the inverted OLEDs have operational lifetimes that are 1.75 times longer than the conventional OLEDs. We then multiplied the average conventional operational P-OLED lifetime by the scaling factor to determine the inverted OLED operational lifetimes for both bottom and top emitting device structures.

The luminous efficacy values were calculated in a similar fashion to the operational lifetime.To determine the luminous efficacy values for the different device architectures, first, we averaged the luminous efficacy values for conventional bottom emitting fluorescent blue OLEDs from references $[10,44,52]$ at a luminance of $1000 \mathrm{~cd} / \mathrm{m}^{2}$. Then, in a similar way to how the operational lifetime of the inverted devices was determined, a scaling factor was taken from reports that directly compared inverted to conventional bottom emitting OLEDs [45,54-57], top emitting to bottom emitting conventional OLEDs [58], and the top emitting to bottom emitting inverted OLEDs [56,59-61]. We then used these scaling factors to calculate the efficacy values from the averaged conventional bottom emitting OLED luminous 
efficacy for each device configuration. Note that the luminous efficacy value of the inorganic LED was based on reported values for mass-produced inorganic LEDs that included light extraction structures and housing[48,50,62-65], which may aid in increasing efficacy values.

\subsection{Definition of Metrics}

Our metrics for this assessment are as follows: (1) device cost per area, $C_{d e v}$, which is the upfront cost to the user at the initial purchase; (2) yearly operating cost, $C_{o p}$, which is the cost to operate the device for $8 \mathrm{~h} / \mathrm{d}$ over a period of one year; (3) optical power cost, $C_{l m}$, which is the cost required to generate the functional unit of $1000 \mathrm{~cd} / \mathrm{m}^{2}$ of optical power for one hour;(4) GHG-CO $\mathrm{CO}_{2} \mathrm{emissions}$ from raw materials extraction and device manufacturing, $\mathrm{GHG}-\mathrm{CO}_{2, \text { dev }}$; (5) yearly $\mathrm{GHG}-\mathrm{CO}_{2} \mathrm{emissions}$ produced from a device operating for $8 \mathrm{~h} / \mathrm{d}, G H G-C O_{2, o p}$. We define $C_{d e v}$ as:

$$
C_{d e v}=C_{m a t}+C_{m a n}
$$

where $C_{\text {mat }}$ is the materials cost for all device layers and $C_{\text {man }}$ is the manufacturing cost. Estimation of $C_{\text {mat }}$ for each device architecture studied here will be discussed in the next section using information obtained from materials suppliers and is the largest contribution to $C_{d e v}$.

$C_{m a n}$ is determined from a percentage range of the total device costsreported for solutionprocessed OPV device manufacturing costs on the lab/pilot scale, i.e.,21 \% to $40 \%$ [6,27,29-51]. Note due to the current state of P-OLED development,large-scale manufacturing methods and practices are currently not optimized or standardized. Additionally, comparisons between manufacturing costs for reelto-reel processed devices and manufacturing costs for devices fabricated on ridged substrates have shown only a slight increase in the percentage contribution of manufacturing costs to total device costs $(\sim 50 \%$ is an upper estimate for OPV devices on glass substrates compared to $21 \%$ to $40 \%$ for OPV on PET substrates). Therefore, we have assumed an average percent contribution of manufacturing costs to total device costs of $30 \%[6,27,29-51]$.Therefore, to determine $C_{\text {man }}$, such that $C_{\text {man }}$ contributes to $30 \%$ of 
$C_{d e v}, C_{\text {man }}$ was taken to be a $43 \%$ of $C_{\text {mat }}$. We do not account for possible differences in manufacturing costs between lighting and display P-OLED technologies such as types of capital equipment (e.g., spray coaters versus ink-jet printers). However, in both cases the active layer, hole transport layer (HTL) and ETL are assumed to be fully solution processed on glass [11,12]. Additionally, as stated earlier, this study focuses on device costsper area;costs associated with (P-O)LED housing, electrical connections, heat sinks and electronic drivers (i.e., balance of system costs) are not included.

We define $C_{o p}$ as:

$$
C_{o p}=\frac{C_{u s e}}{L} * 8 * 365
$$

where $L$ is the operational lifetime of the device and $C_{u s e}$ is the use-phase cost. $L$ is taken to be the time it takes for the luminous efficacy to drop to $50 \%$ of its initial value[68]. $C_{\text {use }}$ is the cost of operation for a device(with area of $1 \mathrm{~m}^{2}$ )over the device's operational lifetime and is defined as:

$$
C_{\text {use }}=C_{\text {elec }} * E_{\text {use }}
$$

where $C_{\text {elec }}$ is taken to be the cost of electricity in the United States (assumed to be $0.0984 \$ /(\mathrm{kW} \mathrm{h})$ [69]), and $E_{\text {use }}$ is the use-phase energy consumption defined as:

$$
E_{\text {use }}=\frac{P_{\text {in }} * L}{1000}
$$

where $P_{\text {in }}$ is operating electrical power for a devicewith an area of $1 \mathrm{~m}^{2} . P_{\text {in }}$ is calculated as follows:

$$
P_{\text {in }}=\frac{M_{v}}{B_{f}} k
$$

where $B_{f}$ is the luminous efficacy and $k$ is a correction factor, which accounts for the performance degradation of the device over time. Here, we assume a constant applied voltage is applied to each device, therefore, $k=0.75$ (i.e., on average, the device operates at $75 \%$ of its initial luminous efficacy over its operational lifetime, $L)$ [68]. $M_{v}$ is theluminous exitance(i.e., the light output power)and is defined as

$$
M_{v}=B * \pi
$$


where $B$ is luminance which we have taken to be $1000 \mathrm{~cd} / \mathrm{m}^{2}$, as discussed earlier in Section 2.1, as it is the standard value used when reporting operational lifetimes of OLED devices [2,24,41-50]. We assume $C_{l m}$ in $\$ / \mathrm{h}$ is then calculated as:

$$
C_{l m}=\frac{M_{v} * C_{e l e c}}{B_{f} * 1000}
$$

Next, $\mathrm{CO}_{2}$ emissions from device production, $\mathrm{GHG}-\mathrm{CO}_{2, \mathrm{dev}}$, which includes the GHG$\mathrm{CO}_{2}$ emissions from raw materials and device fabrication in $\mathrm{kgofCO}_{2}$ is defined as:

$$
G H G-C O_{2, d e v}=\left(E_{m a t}+E_{m a n}\right) * I_{C O 2}
$$

where $E_{m a t}$, in $\mathrm{MJ} / \mathrm{m}^{2}$, is the embodied energy of the raw materials in the devices and $E_{m a n}$, in $\mathrm{MJ} / \mathrm{m}^{2}$, is the direct process energy consumed during device manufacturing. $E_{\text {man }}$, which is taken to be 1.05 times $E_{\text {mat }}$, is determined from averaged ratios of direct process energy to embodied energy in the materialfrom relevant OPV literature [27,29-31]. The average $\mathrm{CO}_{2}$ emission intensity from fossil fuels, $I_{C O 2}$, between 1997 and 2012 for the United States from electricity generation is taken to be 1.90 $\mathrm{kg} /\left(\mathrm{kW}\right.$ h)of $\mathrm{CO}_{2}$ (equal to $\left.0.53 \mathrm{~kg} / \mathrm{MJ}_{\text {of }} \mathrm{CO}_{2}\right)$ [70].Finally, the emission mass flow rate for $\mathrm{CO}_{2}, G H G$ $\mathrm{CO}_{2, o p}$, which is the yearly GHG-CO${ }_{2}$ emission produced from a device (area of $1 \mathrm{~m}^{2}$ )operating $8 \mathrm{~h} / \mathrm{d}$ (in $\mathrm{kg} / \mathrm{a}$ of $\mathrm{CO}_{2}$ )is defined as:

$$
G H G-C O_{2, o p}=\frac{\left(E_{u s e} * I C_{2} * 8 * 365\right)}{L}(9)
$$

\section{Life-Cycle Inventory - Device Architectures and Materials}

The bottom-emitting conventional P-OLEDwas analysed initially as a foundation with which to compare the bottom-emitting inverted, the top-emitting conventional and the top-emitting inverted POLED architectures, and the blue inorganic LED. Schematics of the different P-OLED architectures and the inorganic LED are shown in Fig. 2a-e. 


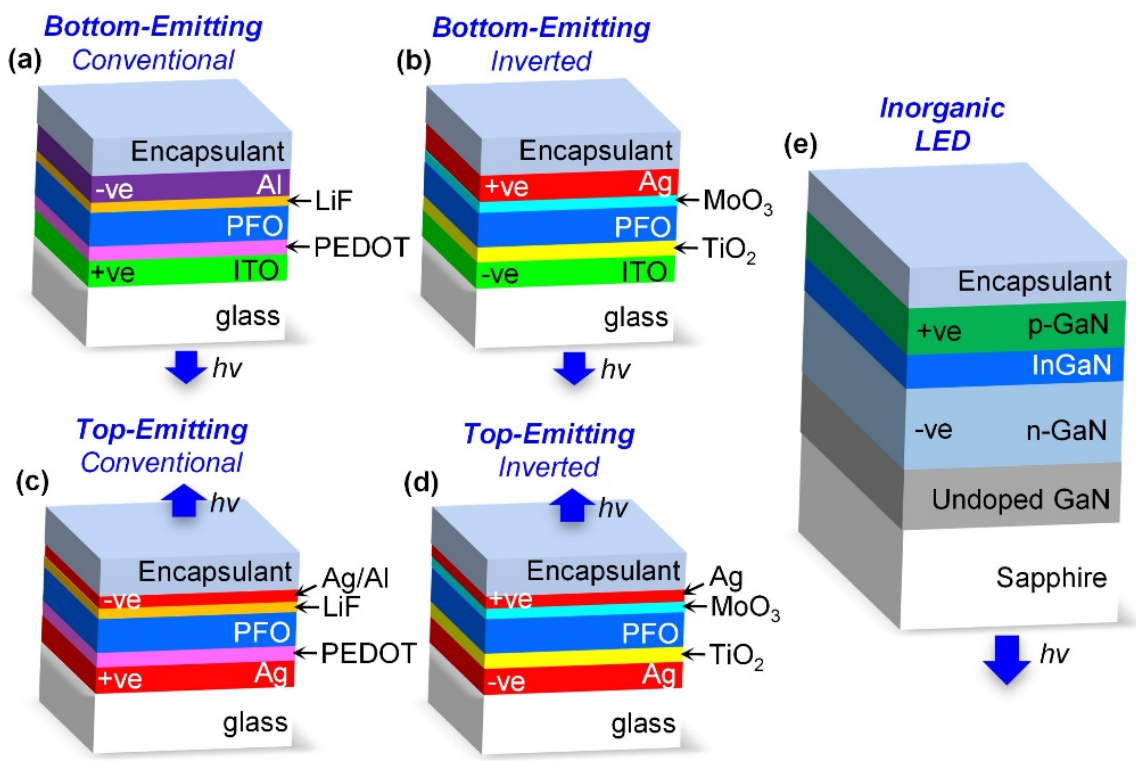

Fig. 2. Schematics of: (a) a bottom-emitting conventional P-OLED, (b) a bottom-emitting inverted POLED, (c) a top-emitting conventional P-OLED, (d) a top-emitting inverted P-OLED, and (e) a blue inorganic LED. The blue arrows with $h v$ (photon energy) labels represent the direction of light emission.

The inventory of materials and average layer thicknesses for each device architecture, obtained from published literature, is included in Table 1.

Table 1. Table of bottom-emitting (conventional and inverted) and top-emitting (conventional and inverted) P-OLEDdevice layer materials, layer thicknesses and corresponding layer functions. The thickness values are an average of values reported in the corresponding referenced literature with the standard deviation shown after the average value. Glass substrates with thickness of $0.192 \mathrm{~mm}$ were assumed for all P-OLED device architectures.

\begin{tabular}{c|ccc}
\hline Device Architecture & Thickness $(\mathbf{n m})$ & Function & References \\
\hline Bottom-Emitting Conventional & & & \\
$\mathrm{ITO}$ & $108 \pm 50$ & Anode & {$[4,22,50]$} \\
$\mathrm{PEDOT}: \mathrm{PSS}$ & $57 \pm 13$ & $\mathrm{HTL}$ & {$[4,22,52,71-75]$} \\
$\mathrm{PFO}$ & $108 \pm 45$ & active layer & {$[4,22,50,72-76]$} \\
$\mathrm{LiF}$ & $2.3 \pm 2$ & ETL & {$[4,71,76]$} \\
$\mathrm{Al}$ & $142 \pm 53$ & Cathode & {$[4,22,50,73,74,76]$} \\
\hline Bottom-Emitting Inverted & & & \\
$\mathrm{ITO}$ & $108 \pm 50$ & Cathode & {$[4,22,50]$} \\
$\mathrm{TiO}$ & $45 \pm 40$ & ETL & {$[77,78]$} \\
$\mathrm{PFO}$ & $108 \pm 45$ & active layer & {$[4,22,50,72-76]$} \\
$\mathrm{MoO}_{3}$ & $11 \pm 7$ & HTL & {$[8,50,77-84]$} \\
$\mathrm{Ag}$ & $35 \pm 30$ & Anode & {$[82-84]$}
\end{tabular}




\begin{tabular}{c|ccc}
$\mathrm{Ag}$ & $125 \pm 29$ & Anode & {$[8,58,85]$} \\
PEDOT:PSS & $57 \pm 13$ & HTL & {$[4,22,52,71-75]$} \\
$\mathrm{PFO}$ & $108 \pm 45$ & active layer & {$[4,22,50,72-76]$} \\
$\mathrm{LiF}$ & $2.3 \pm 2$ & ETL & {$[4,71,76]$} \\
$\mathrm{Al}$ & 2 & Cathode & {$[85]$} \\
$\mathrm{Ag}$ & $17.8 \pm 2.17$ & Cathode & {$[8,85]$} \\
\hline Top-Emitting Inverted & $125 \pm 29$ & & {$[8,58,85]$} \\
$\mathrm{Ag}$ & $45 \pm 40$ & Cathode & {$[77,78]$} \\
$\mathrm{TiO}_{2}$ & $108 \pm 45$ & ETL & {$[4,22,50,72-76]$} \\
$\mathrm{PFO}$ & $11 \pm 7$ & active layer & {$[8,50,77-84]$} \\
MoO & HTL & {$[8,85]$} \\
$\mathrm{Ag}$ & $17.8 \pm 2.17$ & Anode & {$[86,87]$} \\
Blue Inorganic LED & & & {$[86,87]$} \\
sapphire & $10^{6}$ & substrate & {$[86,87]$} \\
undoped GaN & 600 & buffer layer & {$[86,87]$} \\
n-doped GaN & 1500 & ETL & {$[86,87]$} \\
p-doped GaN & 500 & HTL & emitter layer \\
InGaN & 200 &
\end{tabular}

\section{Cost Assessment}

\subsection{Device CostPer Area}

To determine the $C_{d e v}$, we first carried out materials cost calculations to determine $C_{m a t}$ using the mass perareafor each layer of the device and material cost per mass as shown in Table 2. Using the data obtained from Table2, the estimated cost for each layerper area $\left(C_{A}\right)$ in a device was calculated as follows:

$$
C_{A}=m^{*} C_{m}
$$

where $m$ is themassper area and $C_{m}$ is the cost per mass of the material in each layer of the device.

Table 2. The mass of each layer for a device(area of $1 \mathrm{~m}^{2}$ ), the material cost per massvalues and the cost per layer in a particular device are represented for bottom-emitting conventional P-OLED, bottomemitting inverted P-OLED, top-emitting conventional P-OLED, top-emitting inverted P-OLED, and blue inorganic LED architectures [88-97]. Only the materials that are used in aparticular device architectureare represented in the respective column. The cost per layer for the encapsulant is a generic value take from Ref. [32]. Each material layer function is represented by the following superscript characters: ^substrate, \#anode, ${ }^{\times}$HTL, ${ }^{+}$active layer, ${ }^{\text {ETL }},{ }^{*}$ cathode.

\begin{tabular}{|c|c|}
\hline Materials & $\begin{array}{l}\text { Massperarea Cost per } \\
\left(\mathrm{g} / \mathrm{m}^{2}\right) \text { mass }\end{array}$ \\
\hline
\end{tabular}




\begin{tabular}{|c|c|c|c|c|c|c|c|}
\hline & & \multirow{3}{*}{$(\$ / g)$} & \multirow{2}{*}{\multicolumn{2}{|c|}{$\begin{array}{c}\text { Bottom-Emitting } \\
\text { P-OLED }\end{array}$}} & \multirow{2}{*}{\multicolumn{2}{|c|}{$\begin{array}{c}\text { Top-Emitting } \\
\text { P-OLED } \\
\end{array}$}} & \multirow{3}{*}{$\begin{array}{c}\text { Inorganic } \\
\text { LED }\end{array}$} \\
\hline & & & & & & & \\
\hline & & & Conventional & Inverted & Conventional & Inverted & \\
\hline$\overline{\text { Glass }}$ & 474.24 & 0.09 & 42.92 & 42.92 & 42.92 & 42.92 & - \\
\hline ITO & $0.73 \pm 0.34$ & 114 & $83.68 \pm 38.53^{\#}$ & $83.68 \pm 38.53^{*}$ & - & - & - \\
\hline $\mathrm{Al}^{*}(142 \mathrm{~nm})$ & $0.38 \pm 0.14$ & 0.24 & $0.09 \pm 0.03$ & - & - & - & - \\
\hline $\mathrm{Al}^{*}(2 \mathrm{~nm})$ & 0.005 & 0.24 & - & - & 0.001 & - & - \\
\hline $\mathrm{Ag}^{\#}(35 \mathrm{~nm})$ & $0.37 \pm 0.32$ & 6.39 & - & $2.35 \pm 2.01$ & - & - & - \\
\hline $\mathrm{Ag}(17.8 \mathrm{~nm})$ & $0.19 \pm 0.02$ & 6.39 & - & - & $1.19 \pm 0.15^{*}$ & $1.19 \pm 0.15^{\#}$ & - \\
\hline $\mathrm{Ag}(125 \mathrm{~nm})$ & $1.31 \pm 0.30$ & 6.39 & - & - & $8.38 \pm 1.94^{\#}$ & $8.38 \pm 1.94^{*}$ & - \\
\hline PEDOT:PSS & $0.06 \pm 0.01$ & 9.02 & $0.52 \pm 0.12$ & - & $0.52 \pm 0.12$ & - & - \\
\hline $\mathrm{MoO}_{3}{ }^{\times}$ & $0.05 \pm 0.03$ & 10.84 & - & $0.57 \pm 0.36$ & - & $0.57 \pm 0.36$ & - \\
\hline $\mathrm{PFO}^{+}$ & $0.11 \pm 0.05$ & 391 & $43.79 \pm 18.38$ & $43.79 \pm 18.38$ & $43.79 \pm 18.38$ & $43.79 \pm 18.38$ & - \\
\hline $\mathrm{LiF}^{\sim}$ & $0.01 \pm 0.005$ & 31.30 & $0.19 \pm 0.16$ & - & $0.19 \pm 0.16$ & - & - \\
\hline $\mathrm{TiO}_{2}^{\sim}$ & $0.19 \pm 0.17$ & 3.16 & - & $0.59 \pm 0.53$ & - & $0.59 \pm 0.53$ & - \\
\hline Sapphire & 398 & 0.52 & - & - & - & - & 206.96 \\
\hline $\mathrm{GaN}$ & 15.99 & 17.55 & - & - & - & - & 280.62 \\
\hline $\mathrm{GaN}^{+}$ & 0.86 & 17.55 & - & - & - & - & 15.11 \\
\hline $\mathrm{InN}^{+}$ & 0.41 & 188 & - & - & - & - & 76.89 \\
\hline Encapsulant & - & - & 11.49 & 11.49 & 11.49 & 11.49 & 11.49 \\
\hline$C_{m a t}\left(\$ / \mathbf{m}^{2}\right)$ & - & - & $182.68 \pm 57.22$ & $185.39 \pm 59.81$ & $108.48 \pm 20.75$ & $108.93 \pm 21.36$ & $\mathbf{5 9 1 . 0 7}$ \\
\hline
\end{tabular}

By adding the estimated price for each layer (calculated using Equation 10) we determined the estimated $C_{\text {mat }}$ of a devicewith an area of $1 \mathrm{~m}^{2}$ (excluding manufacturing costs) for each architecture: $183 \$ / \mathrm{m}^{2} \pm$ $57 \$ / \mathrm{m}$ (bottom-emitting conventional); $185 \$ / \mathrm{m} \pm 60 \$ / \mathrm{m}$ (bottom-emitting inverted); $108 \$ / \mathrm{m} \pm 21 \$ / \mathrm{m}$ (topemitting conventional); $109 \$ / \mathrm{m} \pm 21 \$ / \mathrm{m}$ (top-emitting inverted); and 591\$/m (inorganic blue LED). In this way the contribution of each layer to the overall $C_{\text {mat }}$ amount for each device could be examined.

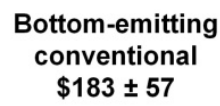

$\$ 183 \pm 57$

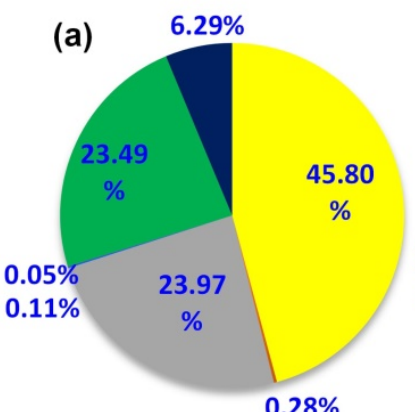

$0.28 \%$

ITO

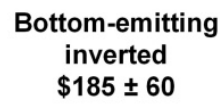

(b)

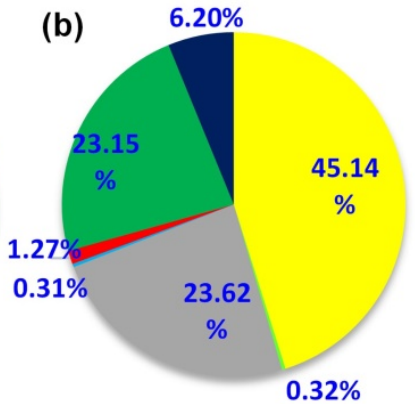

$0.32 \%$ (c)

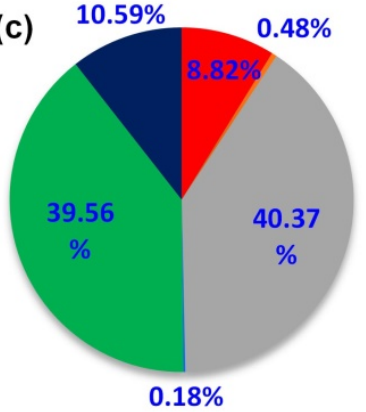

op-emitting conventional $\$ 108 \pm 21$

$0.18 \%$
Top-emitting

inverted $\$ 109 \pm 21$

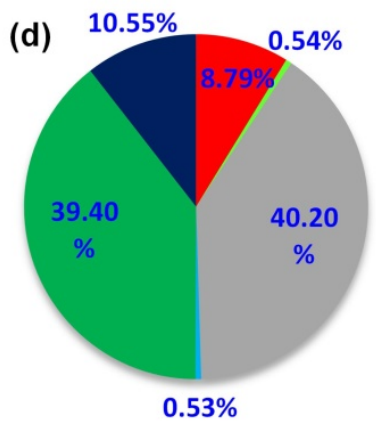

$\mathrm{TiO}_{2} \quad \mathrm{MoO}_{3}$

Fig.3. The percentage cost for each layer in the: (a) bottom-emitting conventional P-OLED; (b) bottomemitting inverted P-OLED; (c) top-emitting conventional P-OLED; and (d) top-emitting inverted POLED. The materials cost, $C_{\text {mat }}$, for each device (area of $1 \mathrm{~m}^{2}$ ) is shown above the corresponding pie chart(i.e., manufacturing costs, $C_{\text {mat }}$, not included). 
As shown in Figure 3 the ITO, PFO and glasslayers contributed the most to $C_{\text {mat }}$ for bottomemitting P-OLEDs (approximately 45\%, 24\% and23\%, respectively) and the PFO and glass layerscontributed the most to $C_{m a t}$ for top-emitting P-OLEDs (both $\sim 40 \%$ ). Despite layer thicknesses of only $\sim 100 \mathrm{~nm}$ for both ITO and PFO (Table 1) they were the most expensive materials, per mass, hence the significant percentage contribution to $C_{d e v}$. Conversely, glass was one of the cheapest materials per mass; however, it was also the thickest layer $(0.192 \mathrm{~mm})$ which resulted in the significant overall cost per area. The metal layers ( $\mathrm{Ag}$ and $\mathrm{Al})$ accounted for less than $9 \%$ of the total cost of the materials in the devices. The ETL and HTL layers were negligible in cost compared to the other layers.As a result, there was very little change in cost on going from a conventional to an inverted device architecture. However, since the top-emitting architectures eliminated ITO, the value of $C_{\text {mat }}$ was reduced by $41 \%$ compared to the bottom-emitting devices. $C_{m a t}$ is $591 \$ / \mathrm{m}$ for the blue inorganic LED device architecture $\left(1 \mathrm{~m}^{2}\right.$ device $)$, with $C_{\text {mat }}$ calculated in a similar fashion to the P-OLEDarchitectures (see Fig. 2 and Table 1).Therefore, $C_{m a t}$ for the blue inorganic LEDwas5.4 timesmore than that of the top-emitting P-OLEDarchitecture. This makes the top-emitting architecture a viable option in terms of $C_{\text {mat }}$ for solid-state lighting or display applications. $C_{d e v}$, which included a material cost, $C_{\text {man }}$, that was calculated as a percentage of $C_{m a t}(43$ $\%$ ) such that $C_{\operatorname{man}}$ contributed to $30 \%$ of $C_{\text {dev }}$ (see Section 2.3), was then determined and the assessment of $C_{d e v}$ is included in Section 4 below.

\subsection{Use-Phase Cost}

We now determinethe performance data (operational lifetime and luminous efficacy) obtained from the literature for each device architecture (Table 3) and how much it would cost to electrically power each architecture in the United States (cost of electricity of $0.0984 \$ /(\mathrm{kW} \mathrm{h})[69])$ over the useful life of each device, i.e., the use-phase cost $\left(C_{\text {phase }}\right)$ using Equations 3-6.

Table 3. The operational lifetime, $L$, and luminous efficacy, $B_{f}$, are represented for the bottom-emitting conventional P-OLED, bottom-emitting inverted P-OLED, top-emitting conventional P-OLED, topemitting inverted P-OLED and blueinorganic LED. 


\begin{tabular}{|c|c|c|c|c|c|c|}
\hline \multirow[t]{2}{*}{$\begin{array}{l}\text { Performance } \\
\text { Parameters }\end{array}$} & \multicolumn{2}{|c|}{$\begin{array}{c}\text { Bottom-Emitting P- } \\
\text { OLED }\end{array}$} & \multicolumn{2}{|c|}{$\begin{array}{l}\text { Top-Emitting } \\
\text { P-OLED }\end{array}$} & \multirow[t]{2}{*}{$\begin{array}{l}\text { Inorganic } \\
\text { LED }\end{array}$} & \multirow[t]{2}{*}{ Sources } \\
\hline & Conventional & Inverted & Conventional & Inverted & & \\
\hline $\begin{array}{c}L(\mathbf{h}) \\
B_{f}(\operatorname{lm} / \mathbf{W}) \\
\end{array}$ & $\begin{array}{c}16000 \\
2.5 \\
\end{array}$ & $\begin{array}{c}28000 \\
3.8 \\
\end{array}$ & $\begin{array}{r}16000 \\
5.1 \\
\end{array}$ & $\begin{array}{r}28000 \\
7.8 \\
\end{array}$ & $\begin{array}{c}50000 \\
7.5 \\
\end{array}$ & $\begin{array}{c}{[2,24,41-46,50]} \\
{[10,44-65]}\end{array}$ \\
\hline
\end{tabular}

As shown in Table 3 the inverted P-OLEDarchitecture has an approximately 75\% longer operational lifetime than the conventional P-OLEDarchitecture(9.6 years compared to 5.5 years, assuming the POLED device operated for $8 \mathrm{~h} / \mathrm{d}$ ). The top-emitting inverted device is the most energy efficientof all of the devices (luminous efficacy of $7.81 \mathrm{~m} / \mathrm{W}$ ), and consumes at least 1.5 times less power that the other POLEDarchitectures during operation. However, the blue inorganic LED has a factor of 1.8 longer operational lifetime than the longest operating P-OLED(17.1 years for the inorganic LED).Using the operational lifetime and luminous efficacy values reported in Table 3 along with Equations 3-6, the usephase cost $\left(C_{\text {phase }}\right)$ for each architecturewas determined; see Figure4.

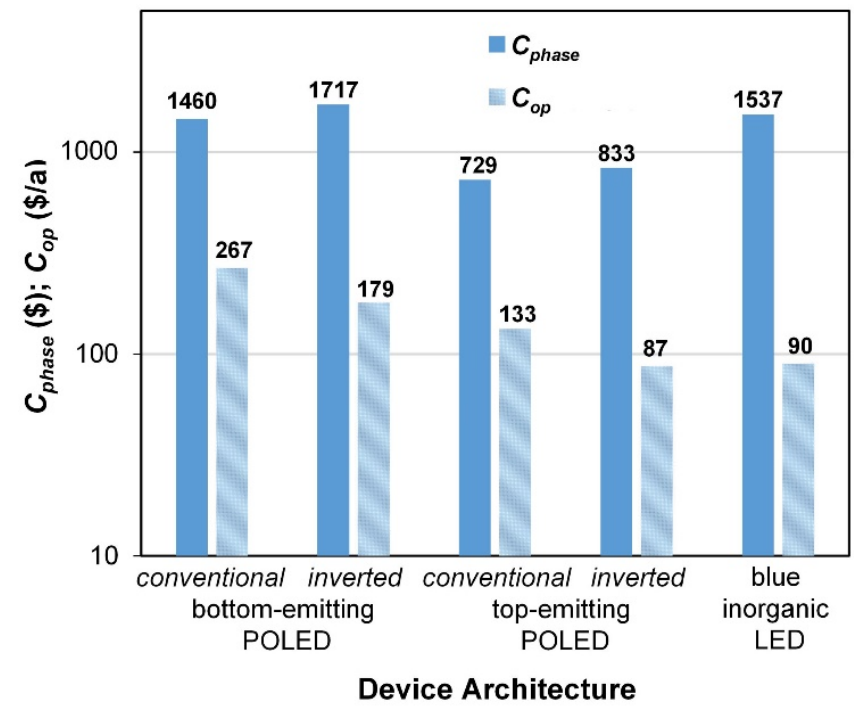

Fig. 4. The corresponding $C_{u s e}$ and $C_{o p}$ values for each P-OLED device architecture and a blue inorganic LED.

We find thatthe bottom-emittinginverted P-OLEDdevice had the highestuse-phase cost $(1717 \$$; 
see Fig.4) of all of the devices and the top-emitting conventional device had the lowest use-phase cost of the P-OLED devices (2.4 times smaller than the bottom-emittinginverted architecture) primarily due itshigherluminous efficacy and shorter operational lifetime (Table 3). The use-phase cost of the blue inorganic LED was $\sim 2.1$ times greater than thetop-emitting conventional P-OLED (729\$and 1537\$, respectively)primarily due to its longer operational lifetime $(50000 \mathrm{~h})$. When the use-phase cost is normalized by the device operational lifetime, we obtain $C_{o p}$, the yearlyoperating cost, for each device (Fig. 4). The top-emitting inverted P-OLED had the lowest operating cost of all P-OLEDs (261\$/a) and cost 8 \$/alower than the blue inorganic LED (269\$/a) due to the higher luminous efficacy of the former $(7.8 \mathrm{~lm} / \mathrm{W})$.

\subsection{Economic Impact}

The following metrics are presented in Table 4 for light-emitting deviceswith areas of $1 \mathrm{~m}^{2}$ : $C_{d e v}, C_{o p}$ and $C_{l m} . C_{d e v}$ (i.e., including materials and manufacturing costs) was the lowest for the top-emitting P-OLEDs and was approximately 5 times cheaper than theblue inorganic LED.

Table 4. The metrics $C_{d e v}, C_{o p}$ and $C_{l m}$, for each P-OLED device architecture and the blue inorganic LED (device areas are $1 \mathrm{~m}^{2}$ in all cases).

\begin{tabular}{l|ccc}
\hline Device Architectures & $\begin{array}{c}\boldsymbol{C}_{\boldsymbol{d e v}} \\
\left(\$ / \mathrm{m}^{2}\right)\end{array}$ & $\begin{array}{c}\boldsymbol{C}_{\boldsymbol{o p}} \\
(\$ / \mathrm{a})\end{array}$ & $\begin{array}{c}\boldsymbol{C}_{\boldsymbol{l m}} \\
(\$ / \mathrm{h})\end{array}$ \\
\hline $\begin{array}{l}\text { Bottom-emitting } \\
\begin{array}{l}\text { Conventional P-OLED } \\
\text { Bottom-emitting }\end{array}\end{array}$ & $261 \pm 82$ & 267 & 0.12 \\
$\begin{array}{l}\text { Inverted P-OLED } \\
\begin{array}{l}\text { Top-emitting } \\
\text { conventional P-OLED }\end{array}\end{array}$ & $265 \pm 85$ & 179 & 0.08 \\
$\begin{array}{l}\text { Top-emitting } \\
\begin{array}{l}\text { Inverted P-OLED } \\
\text { Inorganic LED }\end{array}\end{array}$ & $156 \pm 31$ & 133 & 0.06 \\
\hline
\end{tabular}

This indicates that the top-emitting P-OLEDs are the most attractive device type in terms of up-front costs to the user. The top-emitting invertedP-OLED had the lowest $C_{o p}$ of all of the devices due to its high luminous efficacy(Fig.4), while the bottom-emitting conventionalP-OLEDhad the highest $C_{o p}$. For $C_{l m}$, the 
top-emitting conventional architecture $(0.04 \$ / \mathrm{lm})$ was the best performing of the P-OLEDsand costthesame as the blue inorganic LED. In short, the top-emittinginverted P-OLEDis the most promising P-OLED device architecture in terms of total cost because: (1) it eliminates one of the most expensive layers (ITO) in the device composition; and (2) it has high luminous efficacy in comparison to the otherPOLEDdevice architectures. Furthermore, while the top-emitting P-OLED architecture has a slight advantage over the blue inorganic LED in terms of $C_{o p}$, it is significantly cheaper in terms of $C_{d e v}(\sim 5$ times cheaper). Therefore, even considering the longer lifetime of the inorganic LED (1.8 times longer), the top-emitting P-OLED would still have a lower total cost when factoring in lifetime and replacement device costs (neglecting P-OLED housing and light extraction structures).

\section{Energy and $\mathrm{CO}_{2}$ EmissionsAssessment}

\subsection{Device Embodied Energy}

Powering light-emitting optoelectronic devices is tied to GHG emissions through the indirect production of $\mathrm{CO}_{2}$ during electricity consumption. Furthermore, $\mathrm{GHG}$ emission is linked to the use-phase energy of the P-OLED devices, which is expected to be the most significant energy-consumption stage of the P-OLED life-cycle. As referenced in the Department of Energy study on lighting technology it has been shown that the use phase is the largest contributor to the overall energy consumption of such devices as fluorescent, incandescent, and LED lamps [7]. To illustrate this point, we determined the embodied energy, $E_{\text {mat }}$, in P-OLED devices (areas of $1 \mathrm{~m}^{2}$ ) using literature values for the embodied energy of each constituent layer material and the mass of each layer of the device (Table 5).

Table 5 Embodied energy in MJ/kg of materials in P-OLED devices.

\begin{tabular}{l|cc}
\hline Materials & $\begin{array}{c}\text { Embodied Energy } \\
(\mathbf{M J} / \mathbf{k g})\end{array}$ & Source \\
\hline ITO & 355753 & {$[30,31]$} \\
PEDOT:PSS & 131 & {$[30,33]$} \\
PFO* & 1843 & {$[30,33]$} \\
LiCl $^{\#}$ & 220 & {$[103]$}
\end{tabular}




\begin{tabular}{l|cc}
$\mathrm{Al}$ & 171 & {$[25]$} \\
$\mathrm{Ag}$ & 128 & {$[104]$} \\
$\mathrm{MoO}_{3}$ & 80 & {$[33]$} \\
$\mathrm{TiO}_{2}$ & 118 & {$[33,104,105]$} \\
$\mathrm{Glass}^{2}$ & 16 & {$[25]$} \\
Encapsulant $\left(1 \mathrm{~m}^{2}\right)$ & $10^{\ddagger}$ & {$[31]$} \\
\hline
\end{tabular}

As can be seen in Table 5, ITO and PFO havethe highest embodied energies $355753 \mathrm{MJ} / \mathrm{kg}$ and 1843 $\mathrm{MJ} / \mathrm{kg}$, respectively. We then accounted for the mass of each layer in each P-OLED architecture (Table $6)$.

Table 6. Embodied energy (in MJ) from raw material extraction per layer of material in P-OLED devices with areas of $1 \mathrm{~m}^{2}$ (direct layer process energy not included).

\begin{tabular}{c|cc|cc}
\hline \multirow{2}{*}{ Layer } & \multicolumn{2}{|c|}{ Bottom-Emitting P-OLED } & \multicolumn{2}{c}{ Top-Emitting P-OLED } \\
\cline { 2 - 5 } & Conventional & Inverted & Conventional & Inverted \\
\hline $\mathrm{ITO}$ & 45.89 & 45.89 & - & - \\
$\mathrm{PEDOT}:$ PSS & 0.008 & - & 0.008 & - \\
$\mathrm{PFO}$ & 0.207 & 0.207 & 0.207 & 0.207 \\
$\mathrm{LiCl}$ & 0.001 & - & 0.001 & - \\
$\mathrm{Al}$ & 0.078 & - & - & - \\
$\mathrm{Ag}$ & - & 0.047 & 0.192 & 0.192 \\
$\mathrm{MoO}_{3}$ & - & 0.004 & - & 0.004 \\
$\mathrm{TiO}_{2}$ & - & 0.022 & - & 0.022 \\
$\mathrm{Glass}_{\text {Encapsulant }}$ & 39.52 & 39.52 & 39.52 & 39.52 \\
Total $\left(\boldsymbol{E}_{\boldsymbol{m a t}}\right)$ & 9.96 & 9.96 & 9.96 & 9.96 \\
\hline
\end{tabular}

The resulting embodied energies forP-OLED devices (areas of $1 \mathrm{~m}^{2}$ )were $\sim 96 \mathrm{MJ}$ and $\sim 50 \mathrm{MJ}$ for the bottom-emitting and top-emitting P-OLEDs, respectively. The major contribution to the larger bottom-emitting device embodied energy was ITO, making up approximately $48 \%$ of the embodied energy. The other layers that exhibited significant embodied energies were the glass and encapsulant layers ( 39 MJ and $10 \mathrm{MJ}$, respectively); however, these were still significantly smaller than the ITO embodied energy (which was almost $46 \mathrm{MJ}$ ). Additionally, the embodied energies of all P-OLED devices were approximately an order of magnitude smaller than the embodied energy estimated for the 
inorganicLED(4650 MJ from Ref. 25). However, the total device embodied energy $\left(E_{\text {mat }}\right)$ for each POLED architecturewas substantially lower than the use-phase energy $\left(E_{\text {use }}\right.$; converted to GJ by multiplying its value in $\mathrm{kW}$ h by 0.0036 ) which ranged from $53.4-62.8 \mathrm{GJ}$ for the bottom-emitting P-OLEDs, was a value of 26.7 GJ for the top-emitting conventional P-OLED, and was 30.5 GJ and 56.2GJ for the topemitting inverted P-OLED and the blue inorganic LED, respectively. Therefore, lowering the use-phase energy should have the greatest effect on reducing environmental impacts caused by energy consumption during operation of the P-OLEDs.

\subsection{GHG-Carbon Footprint}

$\mathrm{TheCO}_{2}$ emissions from device production, $\mathrm{GHG}-\mathrm{CO}_{2}$, dev, were calculated for the four different architectures and the blue inorganic LED using Equation 8 and the embodied energies for raw material extractionshown in Table 6. In addition, $\mathrm{GHG}-\mathrm{CO}_{2}$,op, was calculated using Equation 9 and the devices' luminous efficacy and operational lifetime values from Table 3. Both metrics are displayed graphically in Fig. 5 .

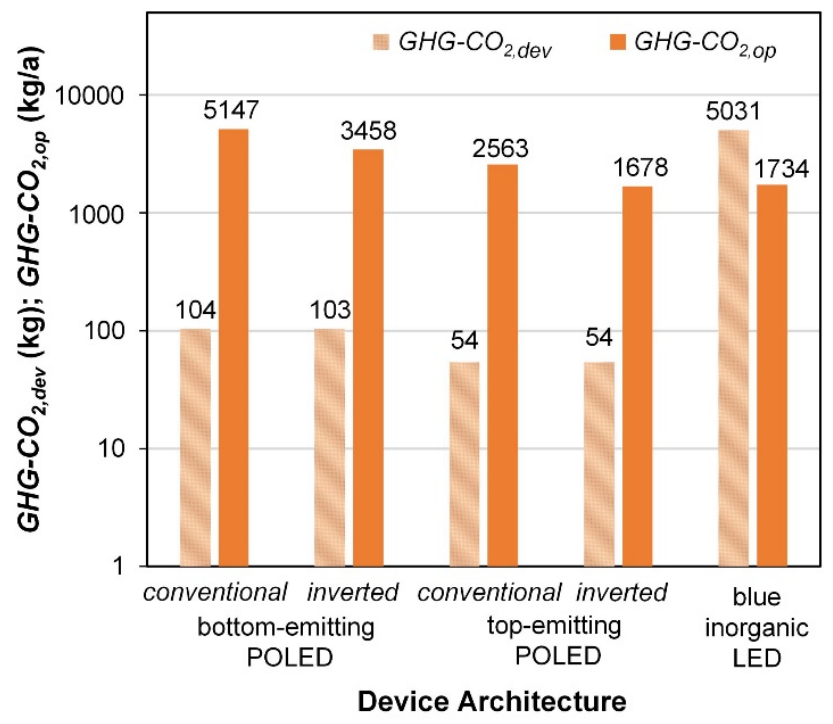

Fig.5. The corresponding GHG- $\mathrm{CO}_{2}$ emissions for raw material extraction and device (1 $\left.\mathrm{m}^{2}\right)$ manufacturing $\left(\mathrm{GHG}-\mathrm{CO}_{2, d e v}\right)$ and yearly GHG-CO $\mathrm{CO}_{2}$ emissions from operation $\left(\mathrm{GHG}-\mathrm{CO}_{2, o p}\right)$ for each P-OLED device architectureand the blue inorganic LED.

The $G H G-C O_{2, d e v}$ is the lowest for the top-emitting P-OLEDs $\left(54 \mathrm{kgofCO}_{2}\right)$ due to the low embodied 
energy for the top-emitting architecture (Table 6). Theblue inorganic LED had a substantially higher GHG-CO ${ }_{2, \text { dev }}\left(5031 \mathrm{kgofCO}_{2}\right)$ compared to all of the P-OLED devices due to the large amount energy embodied in the materials and the correspondingly high direct process energy. The $G H G-C O_{2, o p}$ was lowest for the top-emitting inverted and blue inorganic LED devices $\left(\sim 1678 \mathrm{~kg} / \mathrm{a}\right.$ of $\mathrm{CO}_{2}$ and $\sim 1734 \mathrm{~kg} / \mathrm{a}$ of $\mathrm{CO}_{2}$ respectively) because they are more efficient at converting electrical input power to light (Table 3). The top-emitting inverted P-OLEDproduced approximately $67 \%$ less $\mathrm{CO}_{2}$ during operation than the bottom-emitting conventional P-OLED. Therefore, the top-emitting inverted is the most promising POLEDarchitecture for maintaining a low carbon footprint.

The post-use environmental effects of both P-OLEDs and inorganic LEDs also need to be considered; however, materials toxicity and degradation, as well as materials recycling, are complex and relatively underdeveloped topics in the context of optoelectronic devices. As a result, data is lacking on the environmental impacts and embodied energy associated with processes being used or under development for disposing of or recycling advanced electronic materials [98]. However, metals can be recycled from both types of devices (including indium, tin, silver, gallium and aluminium) either directly or as a by-product [100]. Costs of purifying the recycled metals is likely to be a compounding issue. Furthermore, it has been shown for OPV the glass substrate can be removed and reused with almost no difference in efficiency, and the polymer layers can biodegrade without leaving harmful elements in the environment [34]. While it would be ideal to recycle the P-OLED and LED devices; the energy required to recycle should be considered. Typically, the energy required to recycle a material is less than that for production of the virgin material [25]. All else being equal, based on the embodied energy (Table 6), the energy required to recycle the inorganic LED (4650 MJ) would still be significantly greater than that of the P-OLEDs ( 50-96 MJ) which would make the P-OLED devices the more sustainable choice.

Although recycling removes some of the contaminants; unfortunately, optoelectronic devices (recycling rate of 10\%) are not recycled at the same rate as other hazardous consumer products (recycling rate of $24 \%$ to $90 \%$ ) [99], and large amounts of optoelectronic materials and devices still end up in landfills or recycling centers where they can adversely affect human health and the environment due to 
leeching and evaporation of hazardous substances such as heavy metals [101]. The actual amount of hazardous materials depends on the type of optoelectronics, but as a result of these health and environmental risks governmental agencies havebegun to regulate optoelectronic recycling [102].

\section{Interpretation, Scenario Analysis and Conclusions}

\subsection{Interpretation}

While improvements in the operational lifetime of P-OLEDs must be made to becompetitive with the comparatively long operational lifetime of inorganic blue LEDs, the top-emitting inverted POLEDdevice architectureappears to be the most promising device in terms of projected electrical-tooptical power efficiency, with a high luminous efficacy of $7.81 \mathrm{~m} / \mathrm{W}$ compared to the 7.5 luminous efficacy for the inorganic blue LED. Furthermore, the device costs per areaof P-OLEDs were between 3-5 times cheaper than inorganic LED device costsper area,which would makeP-OLED devices more immediately appealing. The embodied energy in the blue inorganic LED was significantly higher than that for all P-OLED device architectures. However, since the embodied energy was only a small fraction ( $\sim 0.2 \%$ for P-OLEDs and $8 \%$ for the inorganic blue LED) of the use-phase energy of eachP-OLED device, the use-phase was deemed to be the most critical stage to focus on to reduce energy consumption and environmental impacts associated with GHG-CO $\mathrm{CO}_{2}$ emissions.

\subsection{Scenario Analysis}

Theabove interpretation compares laboratory small-scale prototype P-OLEDs to commercialscale (i.e.,mass-produced)blue inorganic LEDs with the P-OLEDs are already cheaper in terms of $C_{d e v}$, and it is likely to remain the case during scale-up of device fabrication.However, OLED large-scale fabrication methods are not welldeveloped and need to be further refined. One of the current obstacles towidespreadcommercialization of OLEDsis their overall high cost due to small-scale manufacturing and use of ridged substrates and vacuum deposition methods during the OLED or P-OLED device fabrication. 
In order to produce P-OLEDs on a large scale and at low cost, the rigid substrate would need to be replaced with a flexible substrate likepolyethylene terephthalate(PET) to enable reel-to-reel processing, materials wastage would need to be decreased, and material types and processing methodswould need to be revaluated. For example, the glass substrate contributed $\sim 25 \%$ and $\sim 44 \%$ (bottom-emitting and topemitting,respectively) to the $C_{\text {mat }}$ and if it was replaced with PET, assuming a thickness of $0.143 \mathrm{~mm}$ $[31,35,108]$, and at a cost of $\sim 0.16 \$ / \mathrm{g}$, the $C_{\text {mat }}$ for each device would be reduced byapproximately $6 \%$ and $10 \%$, respectively [32]. Furthermore, flexible substrates extendthe range of applications for P-OLEDs into not only lighting and standard display options, but also such markets as wearable electronics. In addition, the U.S. Department of Energy estimates that the material utilization rate is as low as $30 \%$ for vapour deposition and as high as $90 \%$ for solution deposition fabrication [9]. In this study, we did not consider fully solution-based fabrication of all layers, thus the deposition of certain layers (e.g., the metal and ITO) by vacuum methods would result in high amounts of materials wastage and increase our predicated $C_{d e v}$. If we account for wastage, $C_{d e v}$ is $548 \$ / \mathrm{m} \pm 384 \$ / \mathrm{m}$ and $561 \$ / \mathrm{m} \pm 225 \$ / \mathrm{mfor}$ the conventional and inverted bottom-emitting P-OLEDarchitectures, respectively; which represent a factor of 2.1 more than without wastage. However, $C_{d e v}$ for the top-emitting device architecture does not increase as significantly when wastage is accounted for because most layers are solution processed (i.e., ITO is eliminated) with $C_{d e v}$ increasingonly by a factor of 1.25 (to $195 \$ / \mathrm{m} \pm 41 \$ / \mathrm{m}$ ) for the top-emitting conventional and inverted device architectures.

Fully solution processed fabrication of P-OLEDs would require alternative material choices to some of those listed in Table 1-2. For example, bulk silver would need to be replaced with silver ink. This alternative material would not have much effect on the overall price as the silver layer(s) do not contribute significantly to $C_{d e v}$; see Fig. 3. However, full solution processing would only be possible for the top-emitting devices due to the vacuum deposition needed for deposition of ITO for conventional POLED devices.In addition, for fully-solution-processed, large-scale production the cost of the materials would decrease by a factor of 2, at least,compared to those reported in Table 2 (resulting in 
$C_{m a t}$ between $63 \$ / \mathrm{m}^{2}$ and $123 \$ / \mathrm{m}^{2}$ for the bottom-emitting P-OLED and between $44 \$ / \mathrm{m}^{2}$ and $65 \$ / \mathrm{m}^{2}$ for thefully-solution-processed top-emitting P-OLED) because of the bulk purchase of material from the suppliers [32-38]. These estimates are on target with estimates reportedby Azzopardi et al., Powell et al. and others for the total device cost of a commercial-scale OPV module which ranges from $45 \$ / \mathrm{m}^{2}$ to $264 \$ / \mathrm{m}^{2}[32-38]$.

When addressing the scalability of OLEDs, changes to device luminous efficacy and operational lifetimeareimportant considerations. Large-scale production is likely to yield devices with lower luminous efficacy and operational lifetimes compared to those for small-scale prototypes, due to the increased likelihood of non-uniformities over large active areas as a result of defects, layer thickness variations and/or electrical shorts [39,109].Reductions in luminous efficacy, in particular,are expected to increase the yearlyoperating cost of these P-OLED devices. While it is expected that there will be a reduction in both luminous efficacy and operational lifetime due to large-scale production,P-OLEDs arecurrently manufactured at the lab- and pilot-scale which makes quantification of the reduction in performance difficult. Therefore, in order to estimate the efficiency and lifetime reduction caused by large-scale production, we draw comparisons with reports on the commercial scale-up of OPVs. Lab-scale efficiencies for optimized polymer-based OPVs have been reported to bebetween $10 \%$ and $12 \%$ (fully solution processed and vacuum evaporated) andOPV modules produced using large-scale processing methods are approximately $2 \%$ efficient; thus indicating in a factor of up to 6 reduction in efficiency during scale-up $[38,39,109]$. Consequently, assuming a similar reduction in the luminous efficacy forthe top-emitting, inverted P-OLED, luminous efficacy would be reduced to $1.3 \mathrm{~lm} / \mathrm{W}$ for adevice fabricated using large-scale production methods.

Furthermore, we can assume a worst-cast operational lifetime of 1 year based on prior studies of OPV devices fabricated by large-scale productionmethods [29,110-112].Thisassumption would reduce the top-emitting inverted P-OLED operational lifetime by a factor of 9.6 (i.e., to $2920 \mathrm{~h}$ ). To illustrate the effect of assuming such significant reductions in luminous efficacy and operational lifetime under a"worst-case" large-scale production scenario, we carried out a scenario analysis using the Monte-Carlo 
methodfor a top-emitting P-OLED where we calculate probability distributions for $C_{o p}, E_{u s e}$ and $G H G$ $\mathrm{CO}_{2, o p}$ under three different scenarios (Fig. 6), assuming relative standard deviationsof the luminous efficacy and operational lifetime of $25 \%$ [29,112-118].
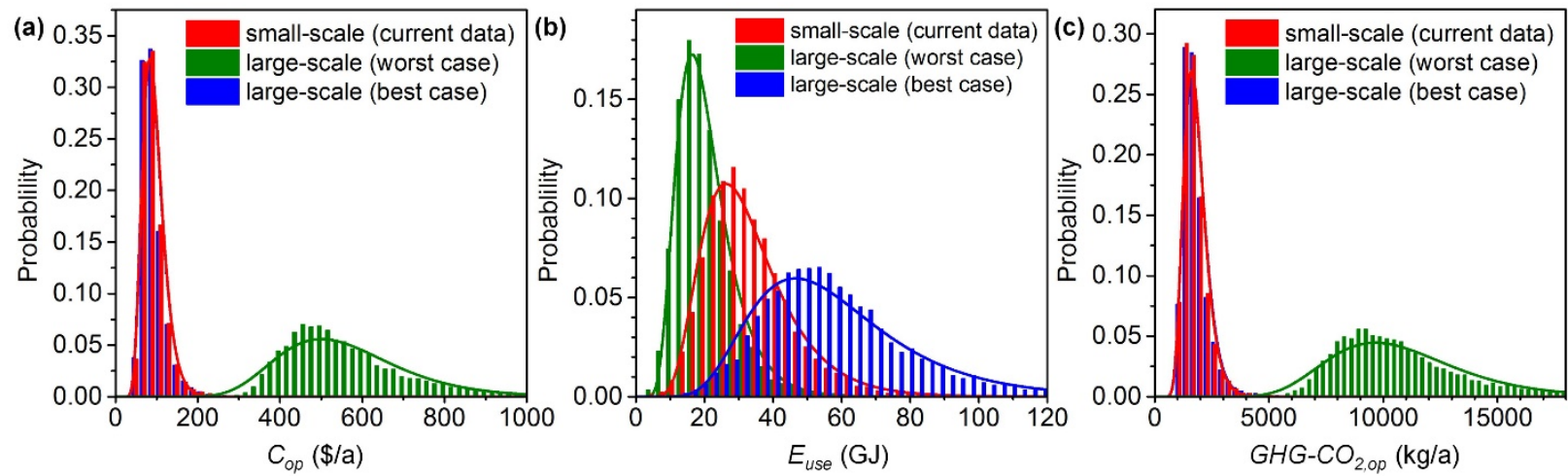

Fig. 6. Histograms showing the probability distribution of (a) $C_{o p}$, (b) $E_{u s e}$ and (c) $G H G-C O_{2, o p}$ for topemitting inverted P-OLEDs $\left(1 \mathrm{~m}^{2}\right)$ generated using the Monte-Carlo method [29] for three different scenarios: small-scale, which assumes luminous efficacy $\left(B_{f}\right)$ and operational lifetime $(L)$ values of 7.9 $\mathrm{lm} / \mathrm{W}$ and $28000 \mathrm{~h}$ (as reported in Table 3); large-scale (worst case), which assumes a factor of 6 reduction in $B_{f}$ compared to the small-scale scenario and a $2920 \mathrm{~h}$ operational lifetime (i.e., 1 year); and large-scale (best case), which assumes a future "best case" large-scale production scenario that results in P-OLEDs with $B_{f}$ and $L$ values of $7.9 \mathrm{~lm} / \mathrm{W}$ and $50000 \mathrm{~h}$, respectively.Normal distributions for $B_{f}$ and $L$ were generated as inputs for the Monte-Carlo analysis, assuming a relative standard deviation of $25 \%$ in $B_{f}$ and $L$ to represent typical performance parameter variations for polymer optoelectronic technologies. The Monte-Carlo analysis was carried out using Microsoft Excel with 10000 random sampling iterations of the input distributions employed to calculate the probability distribution for $C_{o p}$, $E_{u s e}$ and $\mathrm{GHG}-\mathrm{CO}_{2, o p}$.

The first scenario, assumes average luminous efficacy and operational lifetime values achievable using current small-scale production approaches, as reported in Table 3. The second scenario assumes "worst-case" luminous efficacy and operational lifetime values reported above due to large-scale productionmethods. The third scenario assumes a future "best case" scenario in which the luminous efficacy and operational lifetime values at large-scale production are $7.9 \mathrm{~lm} / \mathrm{W}$ (same as currentlyachievable small-scale production value) and $50000 \mathrm{~h}$ (the operational lifetime of a commercial inorganic LED). Figure 6a shows that $C_{o p}$ was similar for small-scale and best-case, large-scale production at $94 \$ / a \pm 33$ \$/aand was significantly lower than $C_{o p}$ for the worst-case, large-scale production (562\$/a \pm 196 $\$ / \mathrm{a})$, because $C_{o p}$ is inversely proportional to luminous efficacyand is insensitive to operational lifetime 
(as it is calculated on a yearly basis). However, $E_{\text {use }}$, is both inversely proportional to luminous efficacyand directly proportional to operational lifetime. Therefore, the larger operational lifetime values for best-case, large-scale production resulted in larger $E_{\text {use }}$ values (58 GJ $\pm 26 \mathrm{GJ}$ ) compared to the smallscale $(33 \mathrm{GJ} \pm 14 \mathrm{GJ})$ and worst-case,large-scale production (21 GJ $\pm 9 \mathrm{GJ})$. In other words, a given device produced under the best-case, large-scale production scenario consumes significantly more energy than a device produced at small-scale or for the worst-cast, large-scale production scenario, simply because it operates for longer. However, $G H G-C_{2, o p}$ exhibited a similar trend to the $C_{o p}$ data as it is also calculated on a yearly basis (and, therefore, is independent of operational lifetime) with small-scale and best-case, large-scale production scenarios exhibiting the lowest emissions.

Based on these scenarios, it is hypothesized that P-OLEDs would have to be mass-produced withluminous efficacy and operational lifetime values reported for small-scale devices (Table 3) in order for them to be viablein terms of the metrics $\mathrm{C}_{o p}$ and $\mathrm{GHG}-\mathrm{CO}_{2}$,op and competitive with commercial inorganic LED counterparts.Luminous efficacy,in particular, is the more critical performance parameter to maintain upon scale-up since the yearly cost and energy to operate P-OLED devices and the yearly GHG- $\mathrm{CO}_{2}$ emissions during operation are significantly greater than for the production of P-OLEDs even under the best-case, large-scale production scenario. For example,the projected best-case $C_{o p}(94 \$ / a)$ and GHG-CO $\mathrm{CO}_{2, o p}\left(\sim 1800 \mathrm{~kg} / \mathrm{a}\right.$ of $\left.\mathrm{CO}_{2}\right)$ for top-emitting, inverted P-OLEDs fabricated using large-scale production are greater than the projected $C_{d e v}\left(\sim 55 \$ / \mathrm{m}^{2}\right)$ and $G H G-C O_{2, d e v}\left(\sim 50 \mathrm{~kg}\right.$ of $\left.\mathrm{CO}_{2}\right)$ for large-scale production.Therefore, we expect that regular replacement of a P-OLED device would be relatively inexpensive and would have low greenhouse gas impacts -particularly in comparison toa commercialinorganic LED with similar luminous efficacy $\left(C_{d e v}\right.$ of $844 \$ / \mathrm{m}^{2}$ and $G H G-C O_{2, d e v}$ of $\sim 5000$ $\mathrm{kg}$ of $\mathrm{CO}_{2}$ ) - thereby making operational lifetime less critical. However, since processing techniques and manufacturing methods have not been standardizedfor P-OLEDs, it is difficult to draw definitive conclusions on whatthe projected device performance parameters should be for P-OLEDs upon scale-up. Therefore, studies such as ours would have to obtain performance parameter data from optimized large- 
scale production processes for P-OLEDs (which are still under development) and draw comparisons with performance parameter data from existing optimized laboratory-scale or pilot-scale processes, which may result in currently unforeseen benchmarks [5]. Finally, it should be noted that for our study we focused only on blue light-emitting P-OLEDs and the metrics would most likely be improved for red and green POLEDs due to their higher efficiencies and longer operational lifetimes.

\subsection{Conclusions}

In conclusion, from a comparison of various P-OLEDs device architectures it was found that the top-emitting inverted P-OLED architecture is likely to be the most promising device architecture to pursue in terms of achieving operational lifetimes and efficiencies that are competitive with commercially-available blue inorganic LEDs and to achieving fully-solution processed large-scale production. Additionally, the device costs per area and embodied energies for the top-emitting P-OLEDs were significantly lower than those for the blue inorganic LED, making P-OLEDs already competitive in terms of up-front cost and energy expenditures. Given these factors and the performance parameters (luminous efficacy and operational lifetime)currently-achievable at lab-/prototype-scale, top-emitting POLEDscould be adopted for portable optoelectronic technologies (e.g., cell phone displays; indicator lights) due to the relatively short use stage of such technologies and inexpensive materials requirements that allow consumers to dispose of them after only 5-10 years. However, theperformance parameters need to remain at current lab-/prototype-scale values during development and scale-up in order to ensure their performance is competitive with inorganic LEDs.Maintaining high luminous efficacy (i.e., electricity-tolight conversion efficiency) upon scale-up will be more important than maintaining long operational lifetimes, since the yearly cost and energy to operate P-OLED devices and the greenhouse gas emissions during operation are significantly greater than for the production of P-OLEDs. Therefore, regular replacement of a P-OLED device would be relatively inexpensive and would have low greenhouse gas impacts;particularly in comparison toan inorganic LED with similar luminous efficacy. 


\section{Acknowledgements}

The authors gratefully acknowledge support from the Jerome Goldstein Scholarship Fund for EcoEntrepreneuring, the Corning, Inc. graduate fellowship program, Department of Education's Graduate Assistance in Areas of National Need (GAANN) fellowship program, National Science Foundation, Grant No. DMR-1309459, Rutgers' Institute for Advanced Materials Devices and Nanotechnology, Rutgers' Aresty Undergraduate Research Fellowship Program and The New Jersey Governor's School of Engineering and Technology Program. The authors thank Dr. Serpil Guran, Kelly Ruffenach, SivarampragadeeshSiva and Xiaojun Wang for their support and useful interactions. 


\section{References}

1. C.F.Wang et al (2013). Functionalized terfluorene for solution-processed high efficiency blue fluorescence OLED and electrophosphorescent devices. Org. Electron. 14, 19581965.

2. D. Fyfe (2009). Organic displays come of age. Nat. Photon. 3, 453-455.

3. F. So and D. Kondakov (2010). Degradation Mechanisms in Small- Molecule and Polymer Organic Light-Emitting Diodes. Adv. Mater22, 3762-3777.

4. C.J.M. Emmott, A. Urbina and J. Nelson (2012). Environmental and economic assessment of ITO-free electrodes for organic solar cells. Sol. Energy Mater. Sol. Cells97, 14-21.

5. S. Lizin et al (2013). Life cycle analyses of organic photovoltaics: a review.Energy Environ. Sci. 6, 3136-3149.

6. S.B. Darling and F. You (2013). The case of organic photovoltaics. RSC Adv. 3, 1763317648.

7. U. S. Department of Energy (2012). Life-Cycle Assessment of Energy and Environmental Impacts of LED Lighting Products, Part I: Review of the Life-Cycle Energy Consumption of Incandescent, Compact Fluorescent, and LED Lamps. SolidState Lighting Program. U.S. Department of Energy. Available from:http://apps1.eere.energy.gov/buildings/publications/pdfs/ssl/2012_LED_Lifecycle Report.pdf (accessed February 2014).

8. P. de Bruyn, D. J. D. Moet and P.W.M. Blom (2012). All- solution processed polymer light-emitting diodes with air stable metal-oxide electrodes. Org. Elect.13, 1023-1030. 
9. U. S. Department of Energy (2014). Solid-State Lighting Manufacturing Research and Development Roadmap. Available from: http://apps1.eere.energy.gov/buildings/publications/pdfs/ssl/ssl_mfg_roadmap_aug2014.p df (accessed October 2015).

10. S.R. Tseng et al (2007). High-efficiency blue multilayer polymer light-emitting diode based on poly(9,9-dioctylfluorene). J. Appl. Phys. 101, 084510 1-4.

11. R.Trattnig et al (2013). Bright Blue Solution Processed Triple-Layer Polymer LightEmitting Diodes Realized by Thermal Layer Stabilization and Orthogonal Solvents. Adv Func. Mat. 23, 4897-4905.

12. H. Zheng et al (2013). All-solution processed polymer light-emitting diode displays. Nat. Commun. 4:1971 doi:10.1038/ncomms2971,1-7.

13. V. Bodrozic et al (2008). The Built In Potential in Blue Polyfluorene-Based Light Emitting Diodes. Adv. Mat. 20,2410-2415.

14. H.Yan et al (2003). High-Brightness Blue Light-Emitting Polymer Diodes via Anode Modification Using a Self-Assembled Monolayer. Adv. Mater.10, 835-838.

15. T. M. Brown et al (1999). Built in field electroabsortion spectroscopy of polymer lightemitting diodes incorporating a doped poly(3,4-ethylene dioxythiophene) hole injection layer. Appl. Phys. Lett. 75, 1679-1681.

16. C.C. Hsiao, A.E. Hsiao, and S.A. Chen (2008). Design of Hole Blocking Layer with Electron Transport Channels for High Performance Polymer Light-Emitting Diodes. Adv. Mater. 20, 1982-1988.

17. T.M. Brown et al (2003). Electronic line-up in light-emitting diodes withalkalihalide/metal cathodes. Appl. Phys. Lett. 93, 6159-6172. 
18. E. L. William et al (2007).Excimer-based white phosphorescent organic light-emitting diodes with nearly 100\% internal quantum efficiency. Adv. Mater. 19, 197-202.

19. S.Y. Kim and J.J. Kim (2010). Outcoupling efficiency of organic light emitting diodes and the effect of ITO thickness. Org. Electron.11, 1010-1015.

20. C.F. Madigan, M. H. Lu and J.C. Sturm (2000). Improvement of output coupling efficiency of organic light-emitting diodes by backside substrate modification. Appl. Phys. Lett.76, 1650-1652.

21. X.Y. Deng (2011). Lighting- Emitting Devices with Conjugated Polymers. Int. J. Mol. Sci. 12, 1575-1594.

22. S. H. Chen and S. C. Chan (2012). Light Enhancement of Plasmonic Nanostructures for Polymer Light-Emitting Diodes at Different Wavelengths. Appl. Phys. Express5, 062001$1-3$.

23. X.H. Li et al (2012). Efficient Inverted Polymer Solar Cells with Directly Patterned Active Layer and Silver Back Grating. J. Phys. Chem. C 116, 7200-7206.

24. J. Zhong et al (2012). Effect of Encapsulation Technology on Organic Light Emitting Diode Lifetime. Opt. Rev.19, 82-85.

25. M. F. Ashby (2013). Materials and the Environment. Butterworth-Heinemann $2^{\text {nd }}$ edition.

26. T Swarr et al (2011) Environmental life cycle costing: a code of practice. SETAC Press, Pensacola, ISBN 978-1-880611-87-6.

27. N. Espinosa and F. C. Krebs (2014). Life cycle analysis of organic tandem solarcells:When are they warranted? Sol. Energy Mater. Sol. Cells. 120, 692-700.

28. L. Tähkämö et al (2013). Life cycle assessment of light-emitting diode downlight luminaire - a case study. Int. J. Life Cycle Assess.18, 1009-1018. 
29. D.Yue et al (2012). Deciphering the uncertainties in life cycle energy and environmental analysis of organic photovoltaics. Energy Environ. Sci.5, 9163-9172.

30. R. Garc1'a-Valverde, J. A. Cherni and A. Urbina (2010). Life cycle analysis of organic photovoltaics. Prog. Photovolt: Res. Appl.18, 535-558.

31. N. Espinosa et al (2011). A life cycle analysis of polymer solar cell modules prepared using roll-to-roll methods under ambient conditions. Sol. Energy Mater. Sol. Cells95, 1293-1302.

32. B. Azzopardi et al (2011). Economic Assessment of Solar Electricity Production from Organic-Based Photovoltaic Modules In A Domestic Environment. Energy Environ. Sci. 4, 3741-3753.

33. Anctil et al (2012). Cumulative energy demand for small molecule and polymer photovoltaics. Prog. Photovolt.: Res. Appl. 21, 1541-1554.

34. Y.S. Zimmerman et al. (2012). Organic photovoltaics: Potential fate and effects in the environment. Environ. Int.49, 128-140.

35. C. Kapnopoulos et al (2016). Fully gravure printed organic photovoltaic modules: A straightforward process with a high potential for large scale production. Sol. Energy Mater. Sol. Cells144, 724-731.

36. M. T. Llyod et al. (2011). Influence of the hole-transport layer on the initial behavior and lifetime of inverted organic photovoltaics. Sol. Energy Mater. Sol. Cells95, 1382-1388.

37. Y. L. Powell and T. Bender (2012). Using stochastic model to determine financial indicator and technical objectives for organic solar cells. Sol. Energy Mater. Sol. Cells107, 236-247. 
38. C. J. Mulligan et al (2014). A projection of commercial scale organic photovoltaic module costs. Sol. Energy Mater. Sol. Cells 120, 9-17.

39. J. Schmidtke (2010). Commercial status of thin-film photovoltaic devices and materials. Opt. Express 18, A477-A486.

40. E.Alsema (1998). Energy requirements of thin-film solar cell modules - a review. Renew. Sustain. Energy Rev.2,387-415.

41. International Organization for, Standardization, ISO 14040 series. Environmental management - life cycle assessment, 2006.

42. H. Bauman and A.M. Tillman (2004). The Hitch Hiker's Guide to LCA. Studentlitteratur AB, Lund, ISBN-10:9144023642.

43. J. H. Youn, S. J. Baek, H. P. Kim, D. H. Nam, Y. Lee, J. G. Leeb, J. Jang (2013). Improving the lifetime of a polymer light-emitting diode by introducing solution processed tungsten oxide. J. Mater. Chem. C1, 3250.

44. M. Roberts, N. Akino, K. Asada, P. Benzie, H. Hamamatsu, M. Hatcher, S. King, E. Snedden, A. Strevens, S. Tanaka, J. Toner, R. Wilson, W. Young, K. Yamamoto, T. Yamada (2013). High efficiency Polymer OLEDs - analysis and progress. SPIE Opt. Photon. 2013 https://www.cdtltd.co.uk/pdf/spie2013-mroberts-cdt.pdf (accessed February 2016).

45. T. -Y. Chu, J. -F. Chen, S. -Y. Chen, C. -J. Chen, C. H. Chen (2006). Highly efficient and stable inverted bottom-emission organic light emitting devices. Appl. Phys. Lett.89, 053503. 
46. S. -Y. Chen, T. -Y. Chu, J. -F. Chen, C. -Y. Su, C. H. Chen (2006). Stable inverted bottom-emitting organic electroluminescent devices with molecular doping and morphology improvement. Appl. Phys. Lett.89, 053518.

47. D. Fyfe (2009). Organic displays come of age. Nat. Photon. 3, 453-455.

48. E. Fred Schubert, Light-Emitting Diodes, Chapter 16, Cambridge University Press, Cambridge, UK (2006).

49. N. Na, J. Jang and H.-J. Suk (2014). Dynamics of Backlight Luminance for Using Smartphone in Dark Environment, Proc. of SPIE9014, 90140I-1-6.

50. M. H. Chang et al (2012). Light emitting diodes reliability review. Microelec. Reliability5, 762-782.

51. Joint Research Centre of the European Commission (2012). International Reference Life Cycle Data System (ILCD) Handbook, General Guide for Life Cycle Assessment, detailed guidance, Joint Research Centre, Institute for Environment and Sustainability, Publications Office of the European Union, Luxembourg, 2010.Available from: http://publications.jrc.ec.europa.eu/repository/bitstream/JRC48157/ilcd handbookgeneral guide for lca-detailed guidance 12march2010 isbn fin.pdf (accessed May 2016).

52. A. Kohler and H. Bassler (2015). Electronic Processes in Organic Semiconductors: An Introduction. Wiley Press,ISBN: 978-3-527-33292-2.

53. B. D. Chin et al (2004). Effects of cathode thickness and thermal treatment on the design of balanced blue light-emitting polymer device. Appl. Phys. Lett. 85, 4496-4498.

54. H. J. Bolink et al (2007). Air stable hybrid organic-inorganic light emitting diodes using ZnO as the cathode. Appl. Phys. Lett. 91, 223501-1-3. 
55. C.Y. Wu et al (2010). Flexible inverted bottom-emitting organic light-emitting devices with semi-transparent metal-assisted electron-injection layer. J. Soc. Info. Display18, 7680.

56. W. Liu et al (2014). Efficient inverted organic light-emitting devices with self or intentionally Ag-doped interlayer modified cathode. Appl. Phys. Lett.104, 0993305-1-4.

57. J. Liu et al (2014). Achieving above 30\% external quantum efficiency for inverted phosphorescence organic light-emitting diodes based on ultrathin emitting layer. Org. Electron. 15, 2492-2498.

58. X. W. Zhang et al (2012). A very simple method of constructing efficient inverted topemitting organic light-emitting diode based on $\mathrm{Ag} / \mathrm{Al}$ bilayer reflective cathode. J.Luminesce.132, 1-5.

59. K.A. Knauer et al (2012). Inverted top-emitting blue electrophosphorescent organic lightemitting diodes with high current efficacy. Appl. Phys. Lett.101, 103304-1-4.

60. S. Hofle et al (2014). Solution processed, white emitting tandem organic light-emitting diodes with inverted device architecture. Adv. Mater.26, 5155-5159.

61. J. Chem (2012). Solution-processable small molecules as efficient universal bipolar host for blue, green, and red phosphorescent inverted OLEDs. J. Mater. Chem.22, 5164-5170.

62. Super Bright LEDs Inc., Super-Blue LED (InGaN), Part Number: RL5-B55a5, https://www.superbrightleds.com/moreinfo/through-hole/5mm-blue-led-15-degreeviewing-angle-5500-mcd/269/ (accessed May 2016).

63. JKL Components Corp., T-1 3/4 Wedge Base 12 Volt LED, Part Number LE-050401B,http://www.jkllamps.com/led/wedgebaseleds(accessed May 2016). 
64. TAIWAN HongGuang 3 W RGB LED Emitter (white) (distributed by Fancy Cost, Item Code 1068112); only specifications for the blue LED component used in this study.

65. CREE, Inc., XImap MC-E RGBW (http://www.cree.com/LED-Components-andModules/Products/XLamp/Arrays-Directional/XLamp-MCE, accessed May 2016); only specifications for the blue LED component was used in this study.

66. O.V. Mikhnenko, P.W.M. Blom and T.Q. Nguyen (2015). Exciton diffusion in organic semiconductors, Energy Environ. Sci. 8, 1867-1888.

67. Euro to dollar conversion factor of 1.35 was employed as of November 2013.

68. N.Narendran et al. (2004) Solid- state lighting: Failure analysis of white LEDs. J.Cryst. Grow.268, 449-456.

69. State Electricity Profile 2010. DOE/EIA-0348(01)/2. Released January 27, 2012. http://www.eia.gov/electricity/state/pdf/sep2010.pdf(accessed October 2015).

70. J. A. deGouw et al. (2014). Reduced emissions of CO2, NOx, and SO2 from U.S. power plants owing to switch from coal to natural gas with combined cycle technology. Earth'sFuture, 2, 75-82, doi:10.1002/2013EF000196.

71. M. Lu, P. Bruyn, H. T. Nicolai and G.J. Wetzelaer (2012). Hole-enhanced electron injection from $\mathrm{ZnO}$ in inverted polymer light-emitting diodes. Org. Elect.13, 1693-1699.

72. V.N. Bliznyuk et al (1999). Electrical and Photoinduced Degradation of Polyfluorene Based Films and Light Emitting Devices. Macromol. 32, 361-369.

73. S. A. Choulis et al (2005). The effect of interfacial layer on the performance of organic light emitting diodes. Appl. Phys. Lett. 87, 113503-1-3.

74. D. Kasama et al (2009). Improved Light Emission Utilizing Polyfluorene Derivatives by Thermal Printing and Solution Process. Proc. SPIE. 7415, 74151N 1-7. 
75. Q. Zhao, S.J. Liuand W. Huang (2009). Polyfluorene-Based Blue-Emitting Materials. Macro. Chem. Phys.210, 1580-1590.

76. T.F. Guo et al (2001). High Performance Polymer Light- Emitting Diodes Fabricated by a Low Temperature Lamination Process. Adv. Funct. Mat. 11, 339- 343.

77. H.J. Bolink et al(2008). Inverted Solution Processable OLEDS using a metal oxide as electron injection contact. Proc. of SPIE 6999, 69992X1-69992X11.

78. H. Choi et al (2011). Combination of Titanium Oxide and a Conjugated Polyelectrolyte for High-Performance Inverted Type Organic Optoelectronic Devices. Adv. Mater. 23,2759-2763.

79. D. Kabra et al (2010). Efficient Single Layer Polymer Light Emitting Diodes. $A d v$. Mater. 22, 3194-3198.

80. F. So and D. Kondakov (2010). Degradation Mechanisms in Small- Molecule and Polymer Organic Light-Emitting Diodes. Adv. Mater.22, 3762-3777.

81. X.H. Li et al (2012). Efficient Inverted Polymer Solar Cells with Directly Patterned Active Layer and Silver Back Grating. J. Phys. Chem. C 116, 7200-7206.

82. H.J. Bolink et al (2010). Phosphorescent Hybrid Organic-Inorganic Light-Emitting Diodes. Adv. Mater. 2, 2198-2201.

83. S.N. Hsieh et al (2009). Surface modification of TiO2 by a self-assembly monolayer in inverted-type polymer light emitting devices. Org. Elect. 10, 1626-1631.

84. J.S. Park et al (2011). High performance polymer light-emitting diodes with n-type metal oxide/conjugated polyelectrolyte hybrid charge transport layers. Appl. Phys. Lett.99, $163305-1-4$ 
85. X.W. Zhang et al (2013). Improving electron injection and microcavity effect for constructing highly efficient inverted top-emitting organic light-emitting diode. Opt. Laser Technol.45, 181-184.

86. Y. Y. Zhang and Y. A. Yin (2011). Performance enhancement of blue light-emitting diodes with a special designed AlGaN/GaN superlattice electron-blocking layer. Appl. Phys. Lett. 99, 221103.

87. R. Dahal, C. Ugolini, J. Y. Lin, H. X. Jiang, J. M. Zavada (2010). $1.54 \mu$ m emitters based on erbium doped InGaN p-i-n junctions. Appl. Phys. Lett. 97, 141109.

88. Ted Pella, Inc. “Glass Microscope Slide"http://www.tedpella.com/histo_html/slides.htm(accessed November 2012).

89. S. Xiao et al (2005). Effects of Solvent on Fabrication of Polymeric Light Emitting Devices. Mat. Lett.59, 694-696.

90. Heraeus Clevios, "Printing Conductivity" $<\underline{\mathrm{http}}: / / \mathrm{www} \cdot h e r a e u s-$ clevios.com/media/webmedia local/media/technical informations flyer/document $\mathrm{H}$ CS_Flyer_CLEVIOS Printing.pdf> (accessed November 2012).

91. Sigma Aldrich "655201 - Poly(3,4-ethylenedioxythiophene)-poly(styrenesulfonate)" http://www.sigmaaldrich.com/catalog/product/aldrich/655201?lang=en\&region=US(acce ssed October 2013).

92. Sigma Aldrich. “571652 - Poly(9,9-di-n-octylfluorenyl-2,7diyl)"http://www.sigmaaldrich.com/catalog/product/aldrich/571652?lang=en\&region= $\underline{U S}($ accessed October 2013). 
93. Sigma Aldrich. "449903 - Lithium fluoride" http://www.sigmaaldrich.com/catalog/product/aldrich/449903?lang=en\&region=US(acc essed October 2013).

94. Sigma Aldrich “266523 -Aluminum” http://www.sigmaaldrich.com/catalog/product/sial/266523?lang=en\&region=USI(access ed October 2013).

95. Sigma Aldrich. "204757-Titanium(IV) oxide" http://www.sigmaaldrich.com/catalog/product/aldrich/204757?lang=en\&region=US(acce ssed October 2013).

96. Sigma Aldrich. "203815 -Molybdenum(VI) oxide" http://www.sigmaaldrich.com/catalog/product/aldrich/203815?lang=en\&region=US(acce ssed October 2013).

97. Sigma Aldrich. “327050-Silver” http://www.sigmaaldrich.com/catalog/product/aldrich/327050?lang=en\&region=US(acce ssed October 2013).

98. O. Tsydenova and M. Bengtsson (2011). Chemical hazards associated with treatment of waste electrical and electronic equipment. Waste Manage. 31, 45-58.

99. J.D. Lincoln et al (2007). Leaching Assessments of Hazardous Materials in Cellular Telephones. Environ. Sci. Technol.41, 2572-2578.

100. http://minerals.usgs.gov/minerals/pubs/commodity/recycle/recymyb01.pdf

101. R. Geyer and V.D. Blass (2010). The economics of cell phone reuse and recycling. Int. J Adv. Manuf. Technol.47, 515-525. 
102. B.H. Robinson (2009). E-waste: An assessment of global production and environmental impacts. Sci.Total Environ. 408, 183-191.

103. J.L. Sullivan and L. Gaines (2012). Status of life cycle inventories for batteries. Energy Convers. Manage.58, 34-148.

104. G.P. Hammond and C.I. Jones (2008). Embodied energy and carbon in construction materials. Proc. Inst. Civil Eng. -Energy161,87-98.

105. G.F. Grubb and B.R. Bakshi (2010). Life Cycle of Titanium Dioxide Nanoparticle Production. J. Ind. Ecol.15, 81-95.

106. N. Osterwalder et al (2006). Energy consumption during nanoparticle production: How economic is dry synthesis? J. Nanopart. Res.8, 1-9.

107. S. J. Hong, Characteristics of IndiumTinOxide (ITO) Glass Re-Used from Old TFT-LCD Panel.Available fromhttps://www.jim.or.jp/journal/e/pdf3/53/05/968.pdf(accessed June 2016).

108. V. Zardetto, T. M. Brown, A. Reale, A. Di Carlo (2011). Substrates for Flexible Electronics: A Practical Investigation on the Electrical, Film Flexibility, Optical, Temperature, and Solvent Resistance. J. Poly. Sci. Part B: Poly. Phys. 49, 638-648. 109. ARENA (2014). Market Technology Analysis Lessons Learnt. Australian Renewable Energy Agency. Available from:http://arena.gov.au/files/2014/06/MarketTechnology-Analysis_Lessons-Learnt.pdf (accessed May 2016).

110. F. C. Krebs, N. Espinosa, M. Hösel, R. R. Søndergaard, M. Jørgensen (2014). 25th Anniversary Article: Rise to Power - OPV-Based Solar Parks. Adv. Mater. 26, 29-39. 
111. M. Corazza, F. C. Krebs, S. A. Gevorgyan (2015). Lifetime of organic photovoltaics: Linking outdoor and indoor tests. Sol. Energy Mater. Sol. Cells143, 467472.

112. C. J. M. Emmott, D, Moia, P. Sandwell, N. Ekins-Daukes, M. Hösel, L. Lukoschek, C. Amarasinghe, F. C. Krebs, J. Nelson (2016). In-situ, long-term operational stability of organic photovoltaics for off-grid applications in Africa. Sol. Energy Mater. Sol. Cells149, 284-293.

113. P. Kumar, C. Bilen, B. Vaughan, X. Zhou, P. C.Dastoor, W. J.Belcher ( 2016). Comparing the degradation of organic photovoltaic devices under ISOS testing protocols.Sol. EnergyMater. Sol. Cells149, 179-186.

114. Z. Ding, J. Kettle, M. Horie, S. W. Chang, G. C. Smith, A. I. Shames, E. A. Katz (2016). Efficient solar cells are more stable: the impact ofpolymer molecular weight on performance of organic photovoltaics. J. Mater. Chem. A4,7274.

115. S. A. Gevorgyan, M. V. Madsen, B. Roth, M. Corazza,M. Hösel, R. R. Søndergaard, M. Jørgensen, F. C. Krebs (2016). Lifetime of Organic Photovoltaics: Status and Predictions. Adv. Energy Mater.6, 1501208.

116. C. H. Peters, I. T. Sachs-Quintana, J. P. Kastrop, S. Beaupré,M.Leclerc, M. D. McGehee (2011). High Efficiency Polymer Solar Cells with Long OperatingLifetimes. Adv. Energy Mater.1, 491-494.

117. T. T. Larsen-Olsen, et al. (2013). A round robin study of polymer solar cells and small modules across China, Sol. Energy Mater. Sol. Cells117, 382-389.

118. A. M. Nardes, C. L. Perkins, P. Graf, J. V. Li, S. E. Shaheen, D. Ostrowski, A. Watte, D. C. Olson, N. Kopidakis (2014). Thermal annealing affects vertical morphology, 
doping and defectdensity in BHJ OPV devices. $40^{\text {th }}$ IEEE Photovoltaic Specialist Conference (IEEE-PVSC) 2575-2580. 